\title{
Geochemical and Behavioral Modeling of Phosphorus and Sulfur as Deleterious Elements of Iron Ore to Be Used in Geometallurgical Studies, Sheytoor Iron Ore, Iran
}

\author{
Aref Shirazi ${ }^{1}$, Adel Shirazy ${ }^{1 *}$, Hamed Nazerian ${ }^{2}$, Shayan Khakmardan ${ }^{1}$ \\ ${ }^{1}$ Amirkabir University of Technology, Tehran, Iran \\ ${ }^{2}$ University of Catania, Catania, Italy \\ Email: *Adel.Shirazy@Aut.ac.ir
}

How to cite this paper: Shirazi, A., Shirazy, A., Nazerian, H. and Khakmardan, S. (2021) Geochemical and Behavioral Modeling of Phosphorus and Sulfur as Deleterious Elements of Iron Ore to Be Used in Geometallurgical Studies, Sheytoor Iron Ore, Iran. Open Journal of Geology, 11, 596-620.

https://doi.org/10.4236/ojg.2021.1111030

Received: October 16, 2021

Accepted: November 19, 2021

Published: November 22, 2021

Copyright $\odot 2021$ by author(s) and Scientific Research Publishing Inc. This work is licensed under the Creative Commons Attribution-NonCommercial International License (CC BY-NC 4.0). http://creativecommons.org/licenses/by-nc/4.0/ (c) (i) (s) Open Access

\begin{abstract}
Sheytoor Iron Ore deposit is located in Yazd province of Iran (Bafq). The most abundant ore is magnetite, which can be seen in the form of mass and granular tissue in various forms of self-shaped, semi-self-shaped and amorphous. The main purpose of this study is to identify the geochemical relationship of phosphorus and sulfur elements and also three-dimensional modeling of mineralization of these elements in iron ore. In order to achieve the research goal, methods such as k-mean clustering technique, concentration-volume fractal as well as block modeling with kriging estimator and Inverse Distance Weighting (IDW) interpolator were used. The model of geochemical behavior of phosphorus and sulfur elements compared to iron is of great importance because these two elements are known as deleterious elements in mineral processing and steelmaking processes, which are the post-mining stages. Existence of geochemical model and identification of elements' behavior towards each other play a key role in optimizing mining operations in order to achieve geometallurgical goals. The results of this study are the three-dimensional model of mineralization of iron, phosphorus and sulfur elements, separation of phosphorus and sulfur mineralization communities and also presenting the model of enrichment community of these two elements. All the results are in line with geometallurgical studies and can optimize the next steps by optimizing the mining process.
\end{abstract}

\section{Keywords}

Geometallurgy, Geochemical Behavior, Phosphorus, Sulfur, Iron Ore, K-Means, Geochemical Modeling 


\section{Introduction}

Iron is the most abundant metallic element in the earth's crust after aluminum. The average abundance (Clark) of iron in the earth's crust is $4.56 \%$. Ten times the enrichment of iron compared to Clark can form an economic deposit [1] [2]. The properties of iron have made it more widely known as the metal that gives us tools, and its ability to make it a major metal in technology using alloys and heat treatment suitable for any application. Iron is the most common metal in everyday life, always in the form of manufactured objects, and is usually covered with a protective coating. Concrete structures contain iron, and electrical machines, including transformers, are iron dependent [3] [4]. Cars are mostly made of iron, and many iron tools are covered with a protective layer of tin [5]. Fasteners, such as nails and screws used, are usually made of iron [6]. The deleterious elements of iron ore are phosphorus, sulfur and silica. Phosphorus causes steel to break. Must be removed or reduced [7]. The sulfur element is a harmful to steelmaking and softens steel and should be removed entirely. Silica is the most expensive annoying element of iron ore, which must be poured out of the melting pot in the form of melt and slag along with a large amount of iron [8]. Iron ore mineralization has existed throughout the geological period from the Proterozoic to the Quaternary, but the major sources of iron ore were formed during the Archaeozoic. In Iran, most sources of iron ore are formed in BafghPosht-e-Badam zone, Sanandaj-Sirjan zone, volcanic-plutonic belt of North Khorasan (Sangan) and other tectonic-magmatic zones [9]. Geochemical behavior is considered as an important tool in identifying the relationships between elements and how deposits are formed [10]. Clustering methods can be of great help in the process of studying geochemical behavior. One of the most important clustering methods is the $\mathrm{k}$-means technique. In this method, bulk data is divided into representative clusters, the members of each of these clusters have similar characteristics to each other [11] [12]. Using the K-mean clustering method, the concentrations of the elements in relation to each other can be predicted. Geochemical behavior of elements to each other can also be identified [13] [14]. Statistics is a powerful tool in geochemical studies that plays an important role in data modeling [15] [16]. Block modeling, in fact, provides a three-dimensional model using data on the concentration of elements [17]. In order to build a three-dimensional model of mineralization, based on the data obtained from drilling exploratory boreholes, various interpolation methods are used. Among the most widely used of these methods are Inverse Distance Weighting (IDW) and Kriging [18] [19]. Mineralization of an element involves diverse mineralization communities. These communities include communities background, anomalies, and enrichment. In two-dimensional (surface) studies, these communities can be identified by tools such as airborne geophysics and remote sensing (satellite image analysis). Each of these methods has already been used in several studies by researchers [20]-[25]. In-depth studies, we will also be able to separate these communities by modeling the concentration of elements 
and using a method such as concentration-volume (C-V) fractal [26]. In addition to geochemical data, which are very efficient in three-dimensional modeling, geophysical data can also play an important role in identifying anomalies and determining deposit characteristics [27] [28] [29] [30]. The purpose of investigating the geochemical behavior as well as three-dimensional modeling of phosphorus and sulfur elements in the present study is to optimize the mining process. Because these deleterious elements are along with iron ore in later stages such as processing and steelmaking. Geochemical and exploratory studies directly affect studies related to mine extraction design as well as mineral processing [31] [32] [33] [34]. The results of this study can be the basis of geometallurgical studies in Sheytoor iron ore mine. Using these results, the mining process can be optimized. In this way, the production of the mine can be commensurate with the feed of the processing plant and the steelmaking process.

\section{Geolocation of Sheytoor Iron Deposit}

The Sheytoor iron deposit is in Yazd province of Iran and is located $78 \mathrm{~km}$ from Bafq city, near the gazestan village. The area of the deposit is approximately 28 $\mathrm{km}^{2}$. You can see the eastern view of the Sheytoor region in Figure 1 [35]. Due to the geological phenomena in this region, this region can be considered as one of the geotourism attractions [36].

\section{Geology}

\subsection{Geological Setting}

The area is located in Yazd province and in central tectonic zone of Iran, which is a small part of the Poshtebadam-Bafq block. In terms of lithology, it has a wide range of alkaline (gabbro-diabaz) to acidic (rhyolitic and rhyodactic) rocks, and includes intrusive, semi-deep and extrusive types. Eastern view of the region and the position of the drilling equipments is shown in Figure 2.

In Figure 2, the locating of 1:1000 map of Sheytoor deposit and 1:20,000 map of the gazestan in the topographic map of 1:50,000 Sheytoor is shown [35] [37].

\subsection{Stratigraphic Units}

In terms of lithology, the area consists of the late precambrian to cambrian volcanic-sedimentary rocks and igneous rocks after that. In the central parts of the

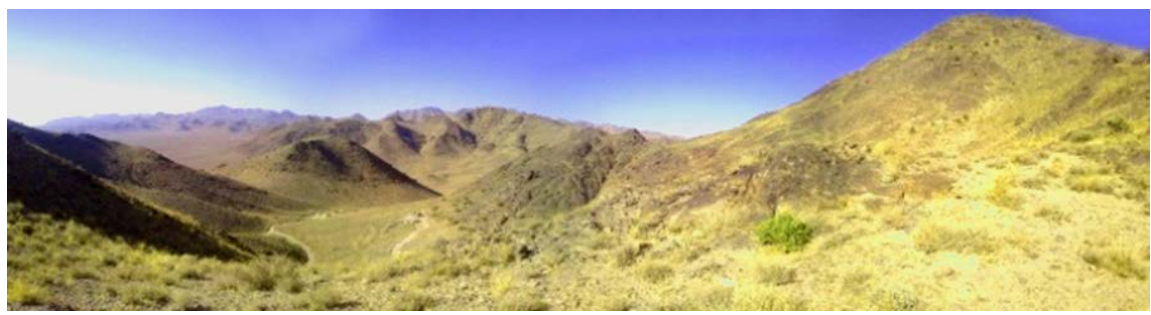

Figure 1. Eastern view of the Sheytoor region. 


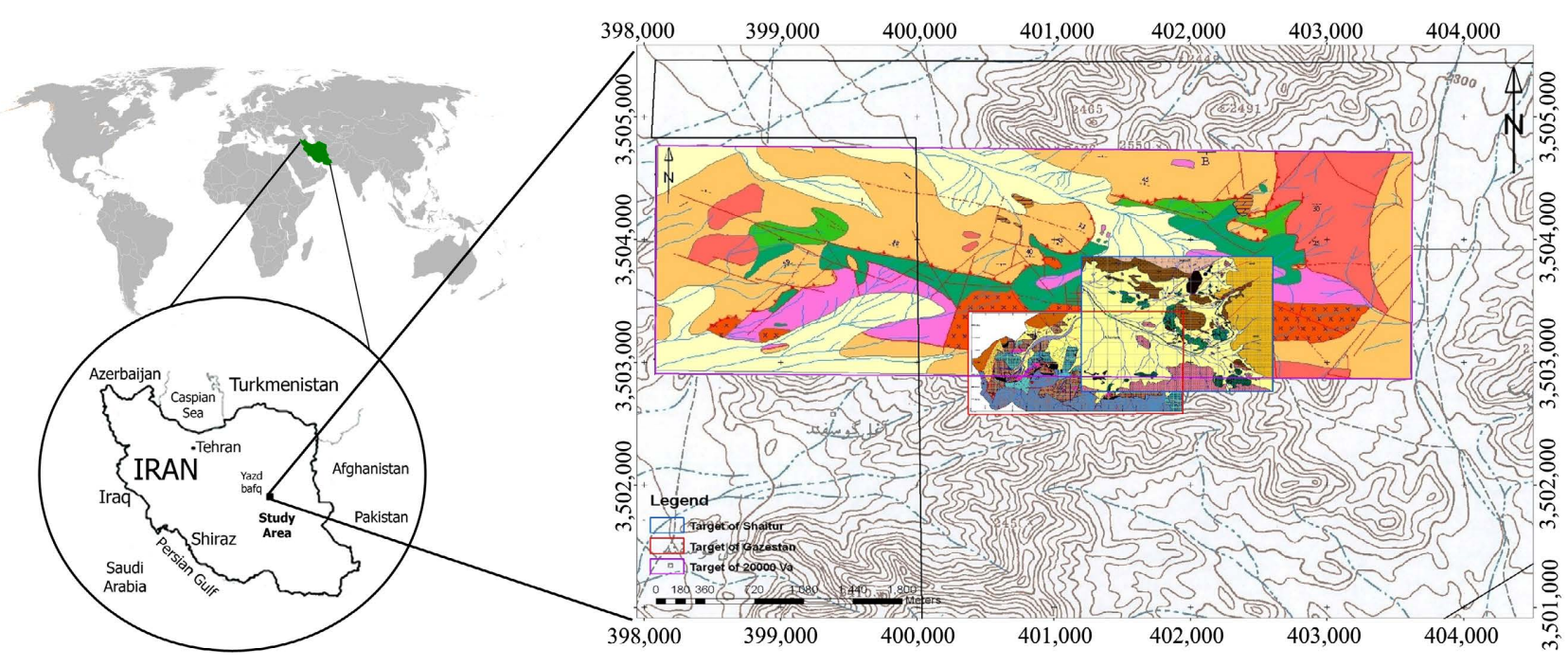

Figure 2. The location of Bafq in Iran map and the locating of 1:1000 map of Sheytoor deposit and 1:20,000 map of the gazestan in the topographic map of 1:50,000 Sheytoor [4].

region, diorite-gabbro and diabase masses occurs as dykes and sills, with porphyritic granite and granite-syenite which cut out older rocks and outcrop. Parts of the ore are covered by present sediments. Metasomatic rocks is as host of mineralization and that has occurred inside it [35] [37].

\subsection{Mineralization}

Mineralization of iron-phosphate is closely related to the region's rocks including gabbro, monzo gabbro, diorite, syenite and diabase which is seen in dark green color. The main ore deposit is as apatite-magnetite mineralization.

Quartz and calcite constitute the main waste material of the mineral. The ore mainly consists of magnetite-apatite in the southern part, usually composed of quartz and calcite in the late stages after mineralization, and in different forms occur within volcanic rocks, microgranite and granodiorite intrusive masses.

Based on microscopic and XRD analysis, the ore minerals include: magnetite, hematite, limonite, goethite, lipidocrocyte, apatite, pyrite, chalcopyrite and rare earth elements minerals such as monazite which can be seen in conjunction with pyroxene, actinolite, thermolite, epidote, chlorite, quartz and calcite waste minerals (Figure 3) [35].

\section{Materials and Methods}

\subsection{Raw Data Preparation Methods}

Before using raw data must identified and replaced censored and outlier data. Censored data is said to be data that among them, due to the high sensitivity limit of measuring devices, a number of data are found to be smaller than the device sensitivity limit. Such data can make statistical problems, because, firstly, statistical methods require a complete set of non-censored data, and secondly, in some cases, such as anomaly separation from background and relative 


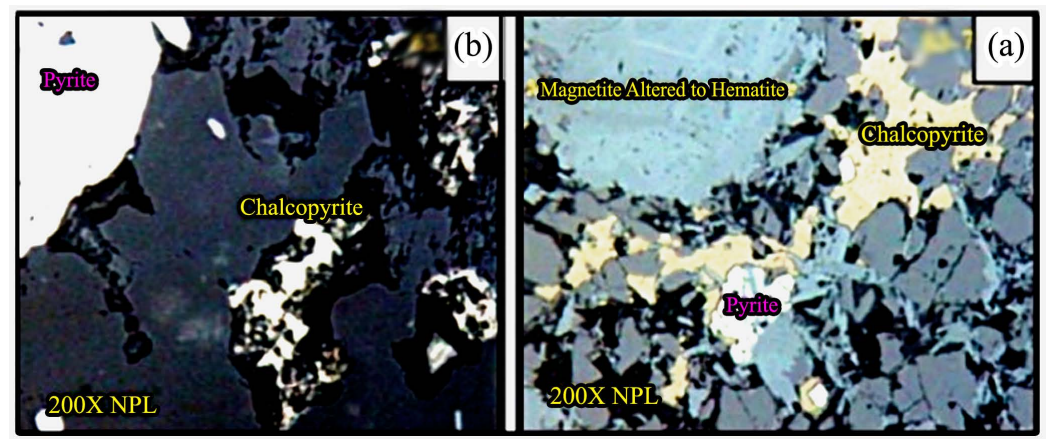

Figure 3. Microscopic images of some ores of the region: (a) Magnetite, hematite, pyrite and chalcopyrite; (b) pyrite and chalcopyrite [4].

measurements, the existence of censored data leads to inappropriate evaluations. If the censored data are identified and replaced, the amount of background and intensity of the anomalies will be calculated more accurately [38].

As the existence of censored data among geochemical data leads to errors, outlier data also have the same effect on the results. In statistics, an outlier is an observation point that is distant from other observations [39] [40]. An outlier may be due to variability in the measurement or it may indicate experimental error; the latter are sometimes excluded from the data set [41]. An outlier can cause serious problems in statistical analyses. Outliers can occur by chance in any distribution, but they often indicate either measurement error or that the population has a heavy-tailed distribution.

Several methods can detect and replace censored and outlier data. In this study, a simple method is used to replace sensor data. In this method, the values of less than sensitivity limit are replaced by $3 / 4$ of data value. The main problem of this method is that it is by no means influenced by the statistical parameters of the data society and is merely a function of the sensitivity limit of the measurement method [38] [42].

In order to identify and replace the outlier data, the doerffel method was used. Doerffel has prepared a graph for determining the threshold of outlier data values, which is provided for two levels of significance of $5 \%$ and $1 \%$ (see Figure 4 ) [35] [42].

To perform the doerffel test, the average $(\bar{x})$ and standard deviation of the data $(s)$ is calculated regardless of the largest amount of data. Then the largest amount of data $\left(x_{A}\right)$ is considered to be outside of the row if it is true in the following Equation (1):

$$
x_{A} \geq \bar{x}+s \cdot g
$$

where " $g$ " is the threshold limit for outlier values which can be calculated by graph shown in Figure 4.

\subsection{Estimation Methods in Modeling}

In this study, in order to grade estimation, methods kriging and inverse distance weighting (IDW) were used. 


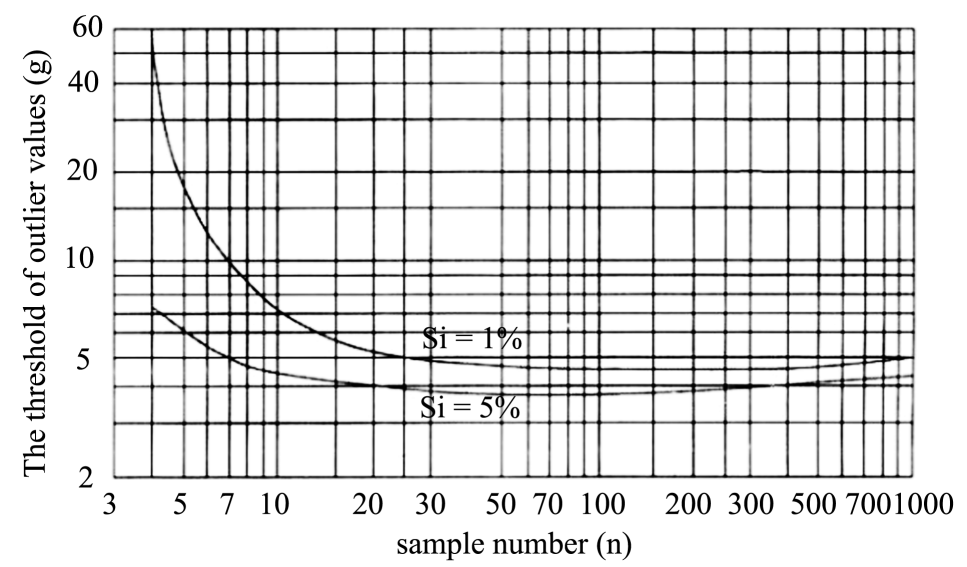

Figure 4. The threshold of outlier values $(g)$ as a function of the sample number $(n)$ and the level of trust.

- Kriging: The basic idea of kriging is to predict the value of a function at a given point by computing a weighted average of the known values of the function in the neighborhood of the point. In geostatistical models, sampled data is interpreted as the result of a random process. The fact that these models incorporate uncertainty in their conceptualization doesn't mean that the phenomenon - the forest, the aquifer, the mineral deposit-has resulted from a random process, but rather it allows one to build a methodological basis for the spatial inference of quantities in unobserved locations, and to quantify the uncertainty associated with the estimator. The kriging function is defined as follows (2):

$$
\hat{z}(x)=\sum_{i=1}^{n} \lambda_{i} z\left(x_{i}\right)
$$

$\lambda_{i}$ is the weight associated with the value of the $x$-variable $x$ at the point $i$ in the case where $\Sigma \lambda=1$ [43].

- Inverse Distance Weighting (IDW): Inverse distance weighting (IDW) is a type of deterministic method for multivariate interpolation with a known scattered set of points. The assigned values to unknown points are calculated with a weighted average of the values available at the known points. IDW is an interpolation method in which estimation is performed based on the values of the nearest points to the point of the weighted inverted distance. The calculation method of the IDW is as follows Equations (3) and (4) [44]:

$$
\begin{gathered}
w(x, y)=\sum_{i=1}^{n} \lambda_{i} w_{i} \\
\lambda_{i}=\frac{\left(\frac{1}{d_{i}}\right)^{p}}{\sum_{k=1}^{N} \lambda_{i}\left(\frac{1}{d_{k}}\right)^{p}}
\end{gathered}
$$

\subsection{Three-Dimensional Modeling}

3D modeling is one of the most common types of modeling to understand the 
mineralization model below the surface of the earth. This modeling, carried out by interpolation of the concentrations of borehole elements at different depths, results in a form of ore below the surface of the earth. Considering the threshold limit, it is possible to see the separated part of the deposit, which is considered as an anomaly. The most common type of 3D model for the description of the ore and the implementation design is "Regular 3D Fixed Block Model". Figure 5 shows an example of a block model [45].

\subsection{K-Means Clustering Method (Behavioral Study)}

K-Means clustering is a method for classifying voluminous data. In this method, using clustering algorithm, data is divided into optimal classes. In this study, using the K-means method, the geochemical behaviors of iron interfering elements are also identified.

The k-means algorithm starts with a given value for $\mathrm{K}$ (number of classes) and tries to estimate the following cases:

- Finding the points as centers of clusters, in fact, these points are the same average points of each cluster.

- Assigning each sample data to a cluster that data has the smallest distance to the center of that cluster [12]. In the simple form of this method, first, the points are selected randomly as much as needed clusters. Then, the data is assigned to one of these clusters according to the similarity and so, new clusters are obtained [46].

- New centers can be calculated for them in each of iterations by repeating the same steps and averaging of data and again the data can be attributed to new clusters [14].

The important steps of this algorithm are summarized as follows [47]:

1) First, $k$ members randomly are selected as the number of clusters among the $\mathrm{n}$ members ( $k$ is the number of clusters).

2) $Z_{j}$ vector is calculated based on Equation (5) which represents the center of each class $C_{\dot{r}}$

$$
z_{j}=\frac{\sum_{x \in c_{j}} x}{\# c_{j}} \text { for } j=1, \cdots, k
$$

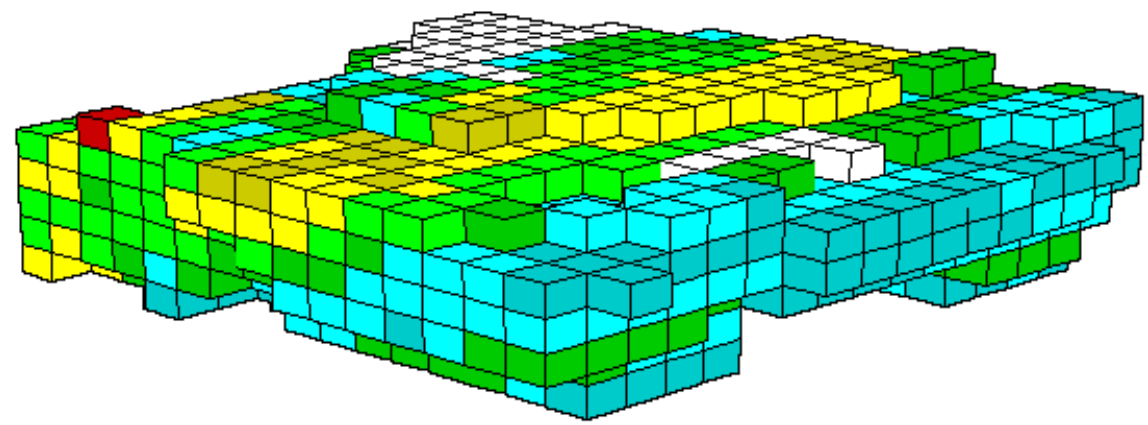

Figure 5. Regular 3D fixed block model [2]. 
3) In this equation, $x$ represents the vector of a sample which is a member of $C_{j}$ and $\# C_{j}$ represents the number of samples which are members of the $C_{j}$ class. It should be noted that relation (6) is used to calculate the center of each class during solving and usually, $k$ samples are randomly selected at the start of the algorithm and are considered as the center of each class [13].

4) Calculate the target function of the classification which calculates the total distance of samples from the center of the classes.

$$
f\left(C_{1}, C_{2}, \cdots, C_{k}\right)=\sum_{j-1}^{k} \sum_{X \in C_{j}}\left|X-z_{j}\right|^{2}
$$

5) Minimize the objective function of Equation (6) and find the proper classification on the $M$ set with the number $k$ of classes.

And a software has been introduced by the author to speed up the operation above [13] [48].

\subsection{Concentration-Volume Fractal Method}

The C-V fractal model, which was proposed by Afzal et al. (2011) [49] for division of mineralized zones and barren host rocks in porphyry deposits, can be addressed as Equation (7):

$$
V(\rho \leq v) \propto \rho^{-\alpha_{1}} ; \quad V(\rho \geq v) \propto \rho^{-\alpha_{2}}
$$

where $V(\rho \leq v)$ and $V(\rho \geq v)$ illustrate two volumes with concentration values less than or equal to and greater than or equal to the contour value $\rho, V$ indicates the threshold value of a mineralized zone (or volume); and $\alpha_{1}$ and $\alpha_{2}$ are characteristic exponents. Elemental threshold values in this model represent boundaries between different mineralized zones and host rocks of mineral deposits. To calculate $V(\rho \leq v)$ and $V(\rho \geq v)$ which are the volumes enclosed by a contour level $\rho$ in a $3 \mathrm{D}$ block model, the borehole data of ore element concentrations were interpolated by utilization of geostatistical estimation [49] [50].

The selection of breakpoints as threshold values appears to be an objective decision because geochemical populations are defined by different line segments in the C-V log-log plot. The straight fitted lines were obtained based on least-square regression [51] [52]. In other words, the intensity of element enrichment is depicted by each slope of the line segment in the C-V log-log plots [26].

\subsection{Drilling and Sampling}

In this study, information of 57 boreholes which are drilled in Sheytoor deposit were used. The depth of the boreholes was between 76 and 475 meters. 1550 samples from cores were systematically collected, the average sampling distance was about 2 meters. All samples were analyzed using ICP-AES method [35]. You can see the geolocations of boreholes in Figure 6.

The statistical parameters of the Fe, $\mathrm{P}$ and $\mathrm{S}$ elements such as mean, standard deviation, variance and etc. were calculated and are shown in Table 1 [37]. 


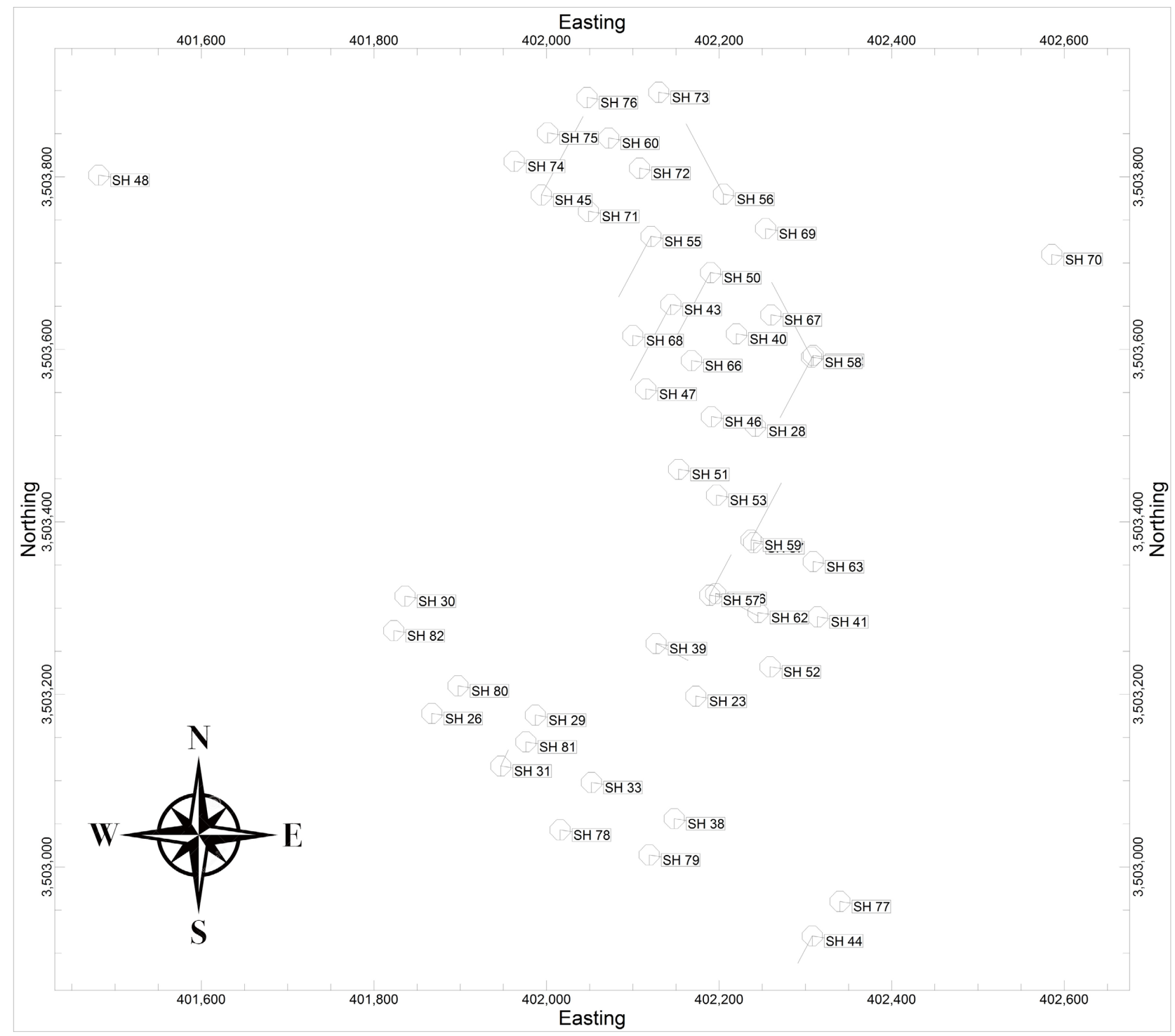

Figure 6. Geolocation of drilled exploratory boreholes in the Sheytoor deposit at surface and depth.

Table 1. Statistical parameters of the Fe, P and S elements.

\begin{tabular}{cccccccccc}
\hline \multirow{2}{*}{ Element Samples } & \multicolumn{2}{c}{$\begin{array}{c}\text { Min } \\
\text { (\%) }\end{array}$} & $\begin{array}{c}\text { Max } \\
\text { (\%) }\end{array}$ & $\begin{array}{c}\text { Mean } \\
\text { (\%) }\end{array}$ & $\begin{array}{c}\text { Median } \\
\text { (\%) }\end{array}$ & $\begin{array}{c}\text { Variance } \\
(\%)^{2}\end{array}$ & $\begin{array}{l}\text { S.D. } \\
(\%)\end{array}$ & Skewness & Kurtosis \\
\hline $\mathrm{Fe}$ & 1550 & 1.08 & 64.47 & 33.65 & 34.32 & 226.2 & 15.4 & -0.01 & -1.16 \\
$\mathrm{P}$ & 1550 & 0 & 3.04 & 0.46 & 0.36 & 0.17 & 0.41 & 2.1 & 6.42 \\
$\mathrm{~S}$ & 1550 & 0 & 5.57 & 0.44 & 0.25 & 0.27 & 0.52 & 3.12 & 15.1 \\
\hline
\end{tabular}

\section{Discussion}

\subsection{Censored and Outlier Data}

The explained method in Section 3.1 was used to replace the Fe censored data values. Using doerffel method for identifying outliers, data were analyzed. Regarding iron cadmium data, the values of $42.10 \%$ were considered as larger val- 
ues and then calculated the average and standard deviations of data without considering these values, which was $24.78 \%$ and $9.91 \%$, respectively.

According to the graph that is given in Figure 4 and number of samples (1550 samples), the amount of (g) parameter, was estimated " 4.4 ".

So using doerffel relationship (8):

$$
x_{A} \geq \bar{x}+s \cdot g
$$

Outlier limit $\geq 24.78+(9.91 \times 4.4)=68.38 \%$

The highest Fe content in the analysis data is $65.5 \%$ which this value is less than outlier limit (68.38\%). Therefore, it does not count as an outlier value. So some value is not removed from the raw data as outlier data.

\subsection{Raw Data Computing}

In this section, the frequency distribution chart (histogram) is drawn to examine the various characteristics of our statistical society. The statistical society of the study is a set of geochemical information in the form of iron element concentration derived from systematic sampling of exploratory boreholes which are drilled in the Sheytoor mining area. The histogram of our statistical society is shown in Figure 7. The purpose of this study is geochemical modeling of iron interfering elements (Phosphor and Sulfur) and to identify the behavior of these elements in relation to the Fe.

The statistical parameters of the Iron, Phosphorus and Sulfur elements such as mean, standard deviation, variance and etc. were calculated and are shown in Table 1.

\subsection{D Geochemical Model of Fe Element}

In this Model, by using the "Inverse Distance Weighting (IDW)" interpolation

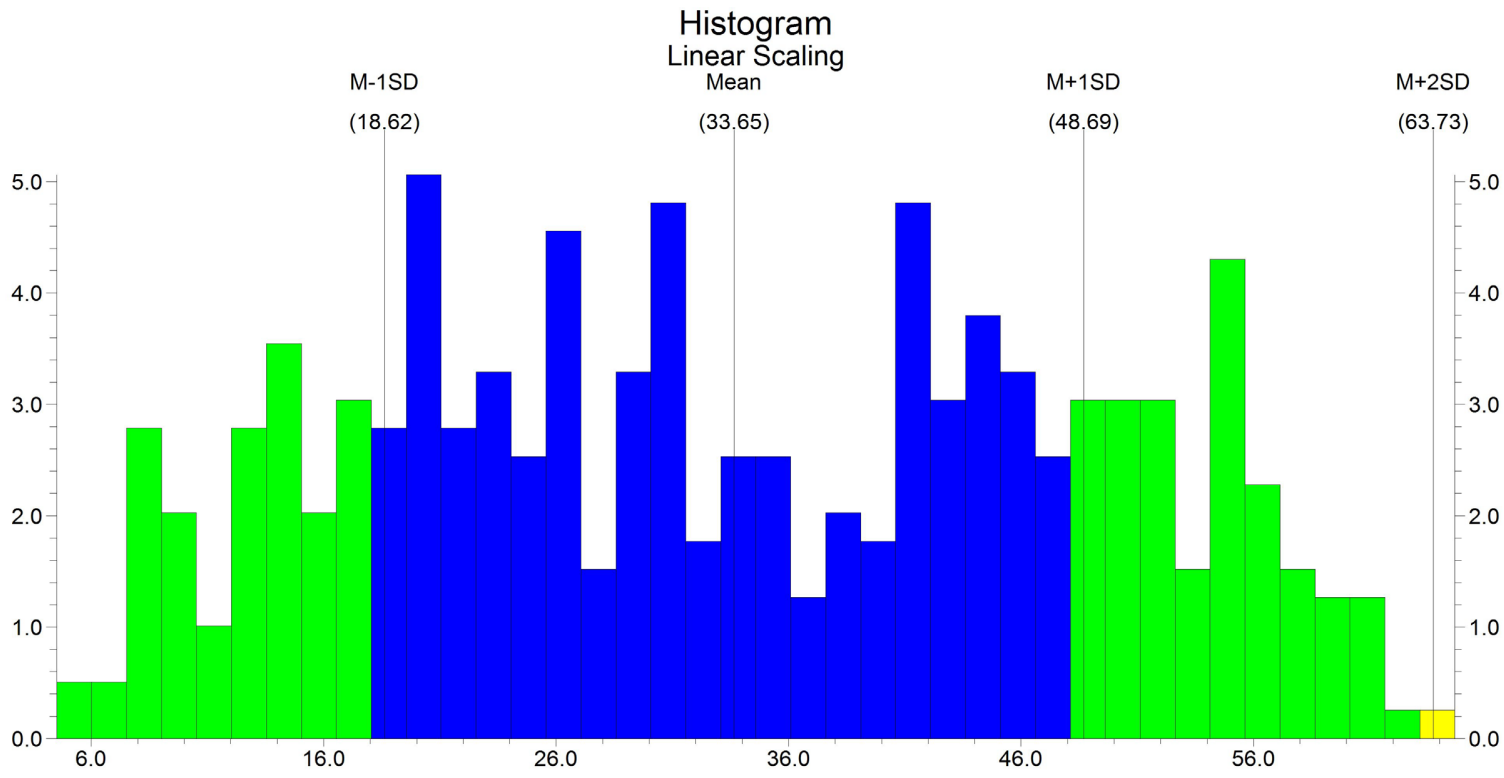

Figure 7. Histogram of the Fe element on a linear scale with due to the sum of the mean with the standard deviation. 
method, interpolation and estimation of the iron element concentration according to the boreholes (Figure 8) were studied at all points of the study area. Then, 3D block model of subsurface mineralization was modeled.

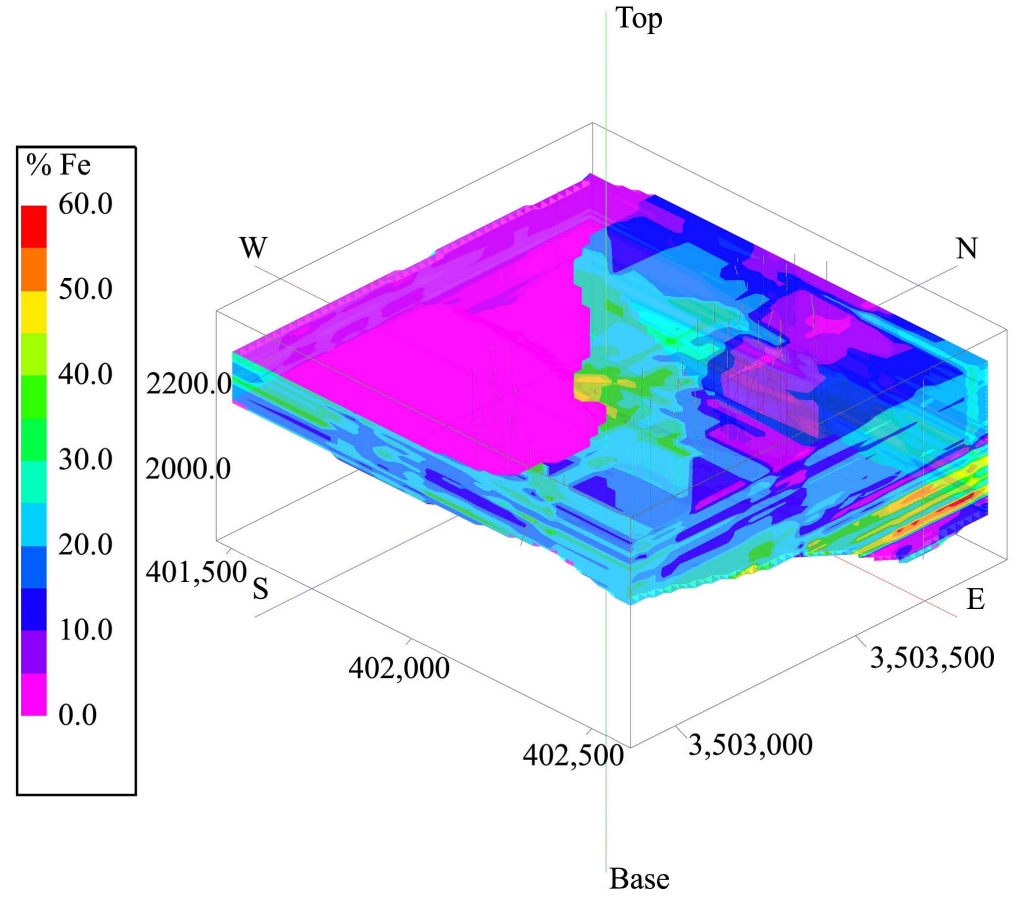

(a)

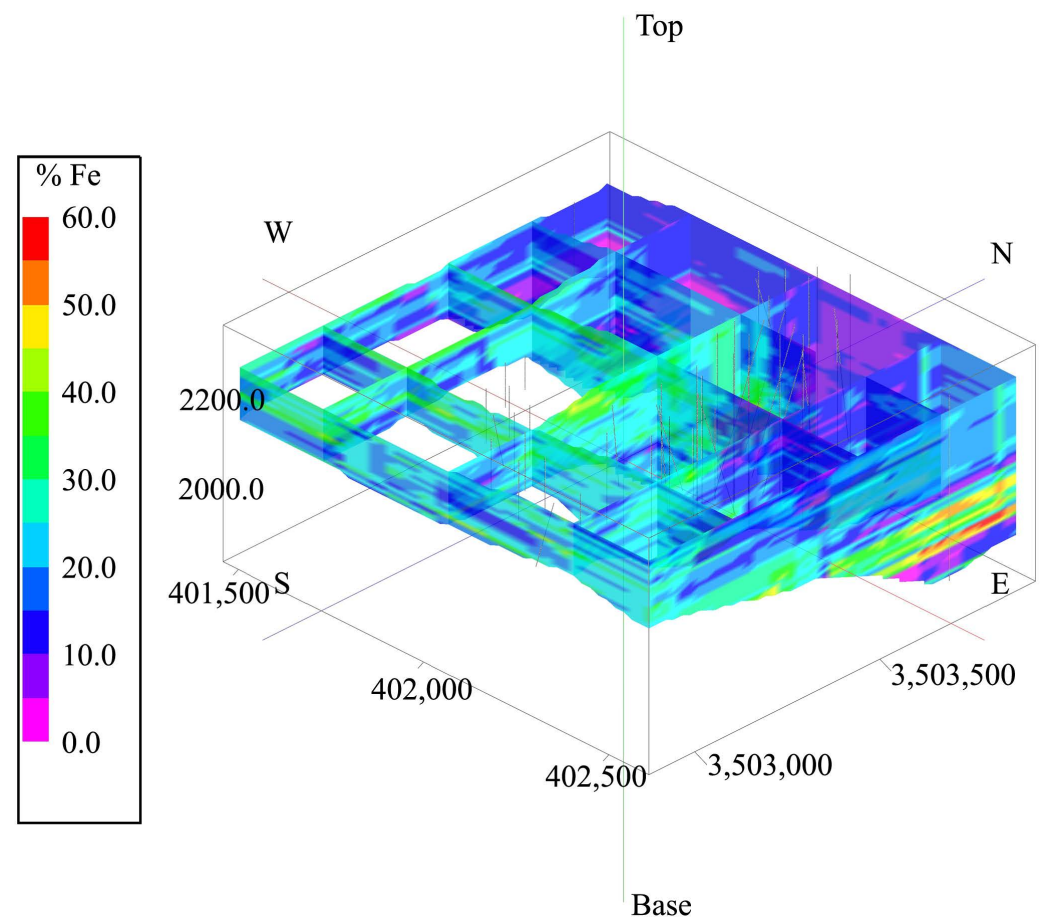

(b)

Figure 8. 3D block model of Fe mineralization in Sheytoor iron deposit, regardless of the cut-off grade. (a) solid model (b) intersection model. 


\subsection{Geochemical Behavior of Disturbing Elements}

In this section, using the K-Means clustering method, how the elements behave to each other is discussed. The elements associated with the mineralization of iron in Sheytoor area, are sulfur and phosphorus, which can be effective in the processing and extraction of pure metal. Therefore, in this section, the geochemical behavior of iron, phosphorus and sulfur in relation to each other was investigated in pairs.

\subsubsection{Geochemical Behavior of Iron and Phosphorus}

In order to identify the geochemical behavior of iron and phosphorus elements relative to each other, the profile of classes and the desirability of each sample for the optimal classification performed with the values of $K=3$ to $K=6$ in Figure 9 for the two elements phosphorus and iron it has been shown.

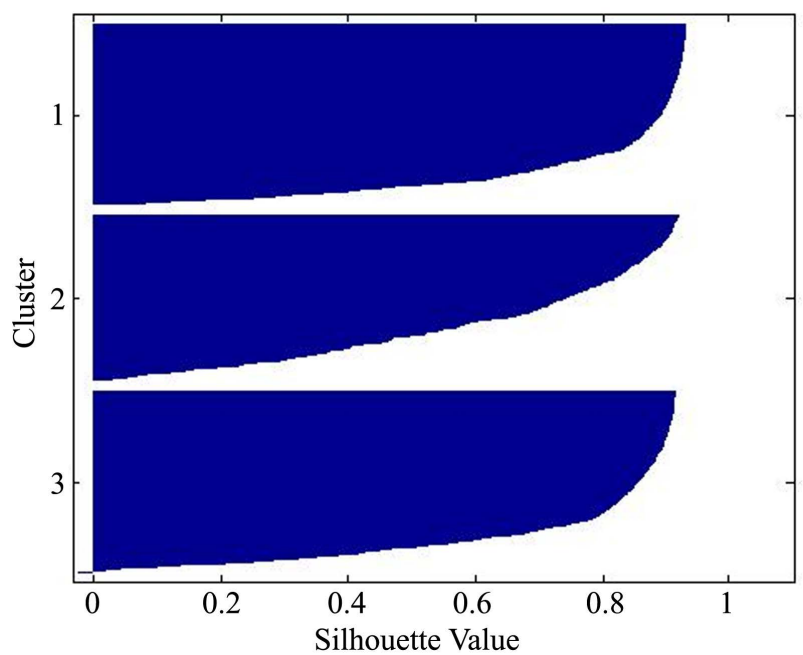

(a)

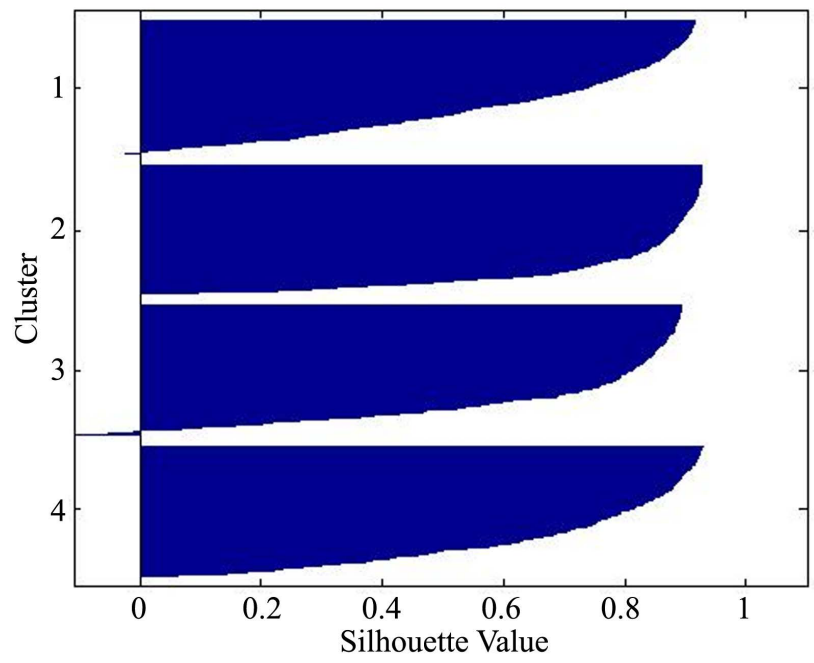

(c)

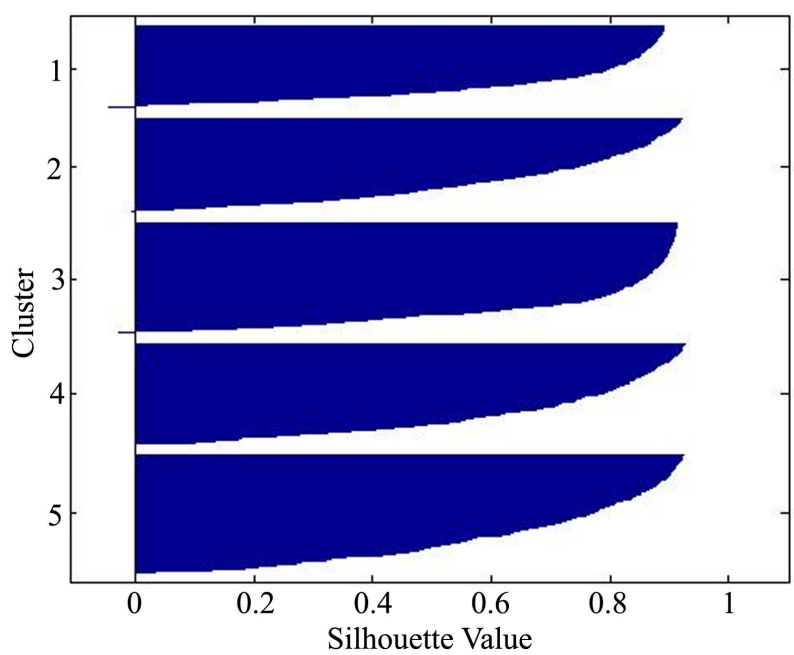

(b)

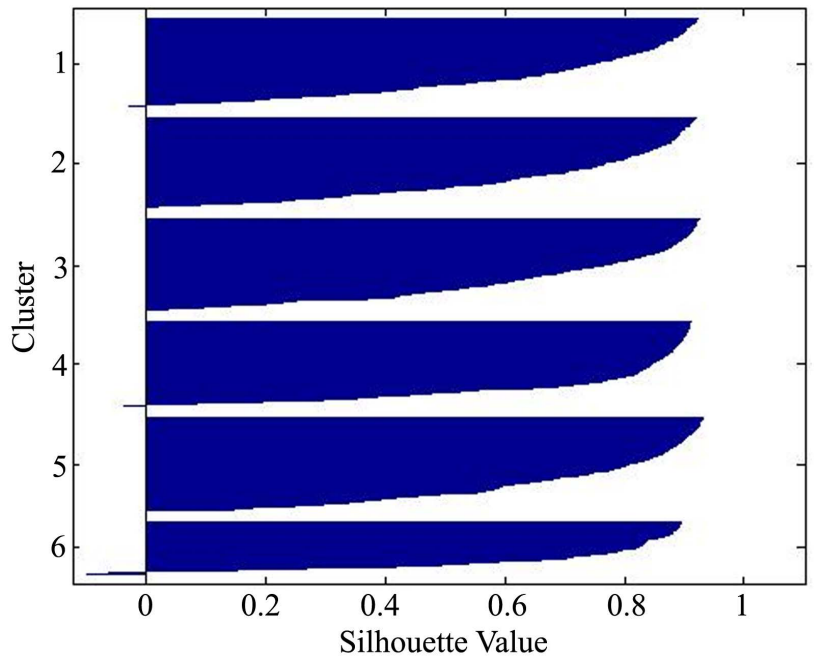

(d)

Figure 9. Cluster profiles and utility values with 3 to 6 classes related to Fe and P concentration. (a) Classification with 3 classes; (b) Classification with 4 classes with an average value of 0.883; (c) Classification with 5; (d) Classification with 6 classes. 
In order to find the best clustering according to the mentioned profiles, the graph of the mean value of the utility function $(S(i))$ of the average for the number of classes ( $K=3$ to $K=10$ ) is given in Figure 10 .

According to the above diagram, the highest value of the utility function, which indicates the optimal clustering, occurred in the number of clusters 3 . Therefore, we use this clustering to investigate the geochemical behavior of phosphorus with respect to iron. The centers of the designated categories for $K=$ 3 are plotted in Figure 11.

Based on this classification, according to the diagram presented in Figure 11, with the increase of iron concentration in Sheytoor deposit, the amount of phosphorus concentration also increases. The behavior of these two elements in relation to each other is nonlinear. The fitted curve with regression coefficient $\mathrm{R}^{2}$ $=1$ is a quadratic curve whose equation is given in Equation (9).

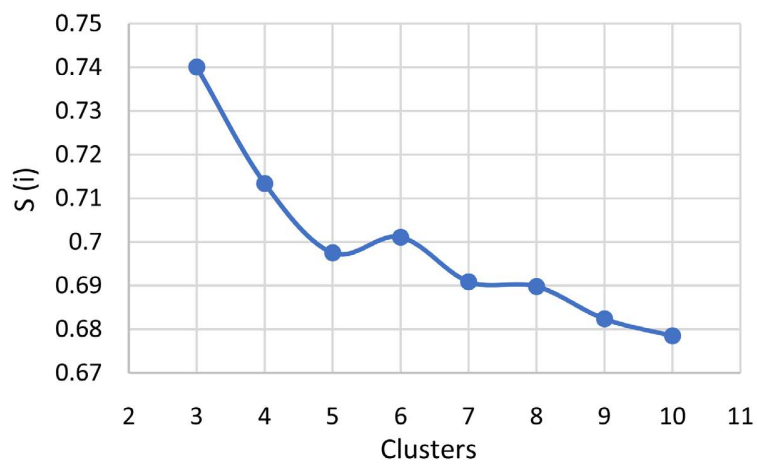

Figure 10. Graph of the average value of the utility function against the number of classes in the behavior of iron and phosphorus.

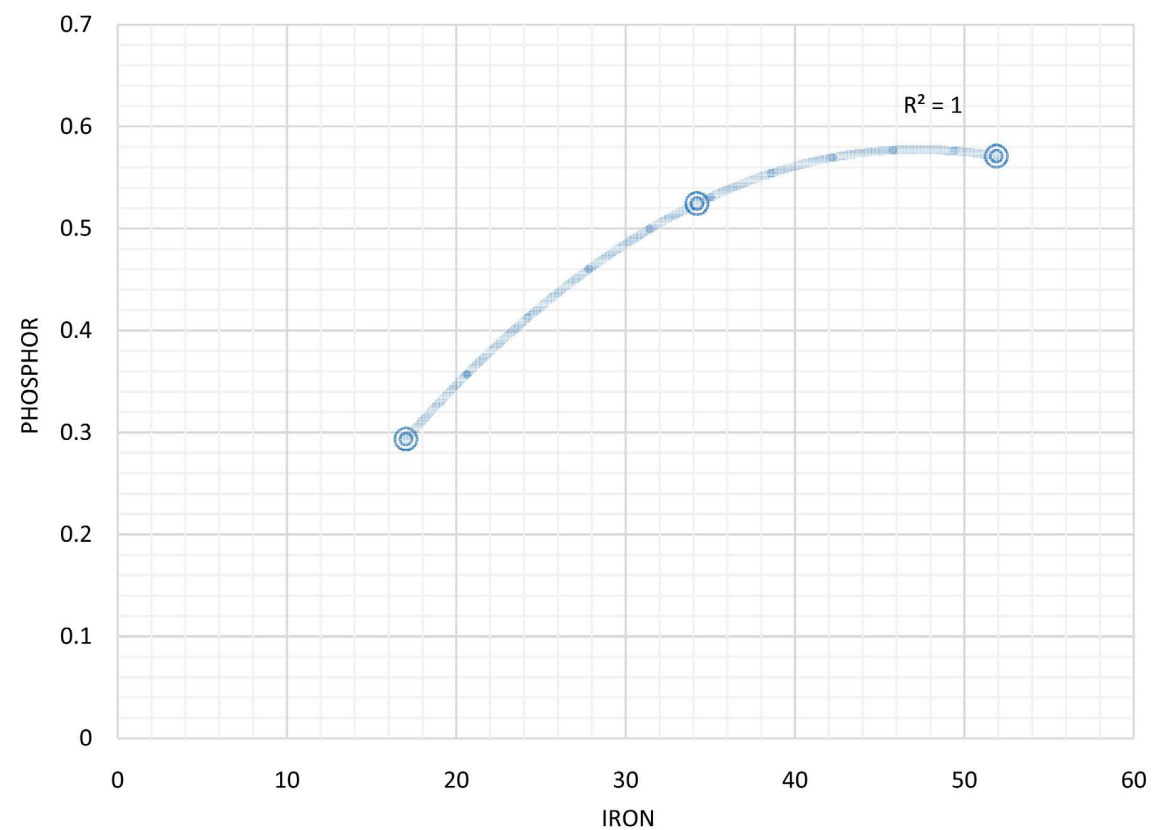

Figure 11. Concentrations of iron and phosphorus in class centers for three-class clustering. 


$$
\mathrm{P}=-0.0003(\mathrm{Fe})^{2}+0.0293(\mathrm{Fe})-0.1162
$$

Using the above equation, we can calculate the concentration of each element of iron and phosphorus relative to each other.

\subsubsection{Geochemical Behavior of Iron and Sulfur}

In order to investigate the geochemical behavior of iron element compared to sulfur element in Sheytoor deposit. To select the best classification, the graph of the mean value of the utility function $(S(i))$ versus the number of classes for iron and sulfur elements and clustering profiles for $K=3$ to $K=6$ are presented (Figure 12 and Figure 13). Because the value of the utility function was always decreasing for categories with more than $K=10$, only $K=1$ to $K=10$ was considered.

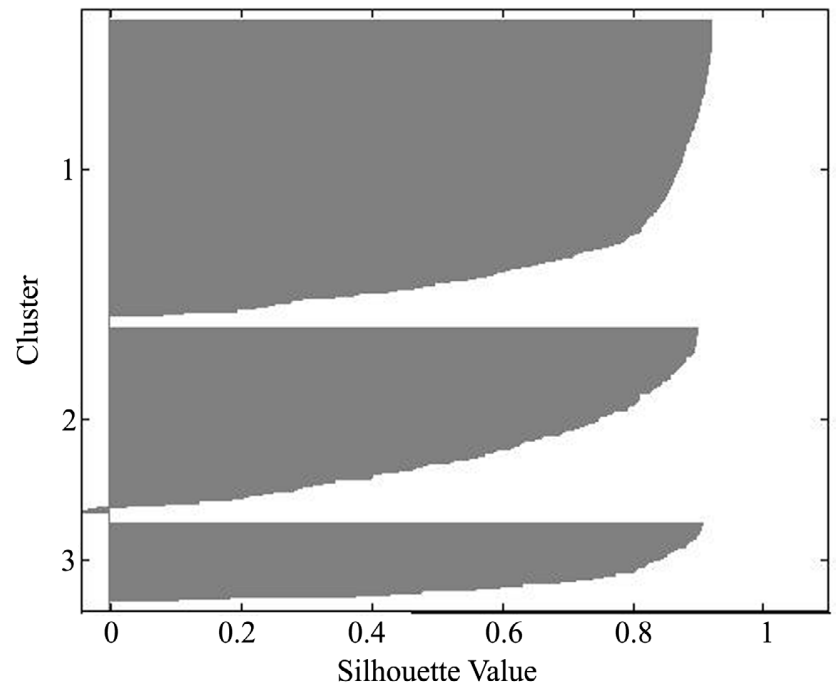

(a)

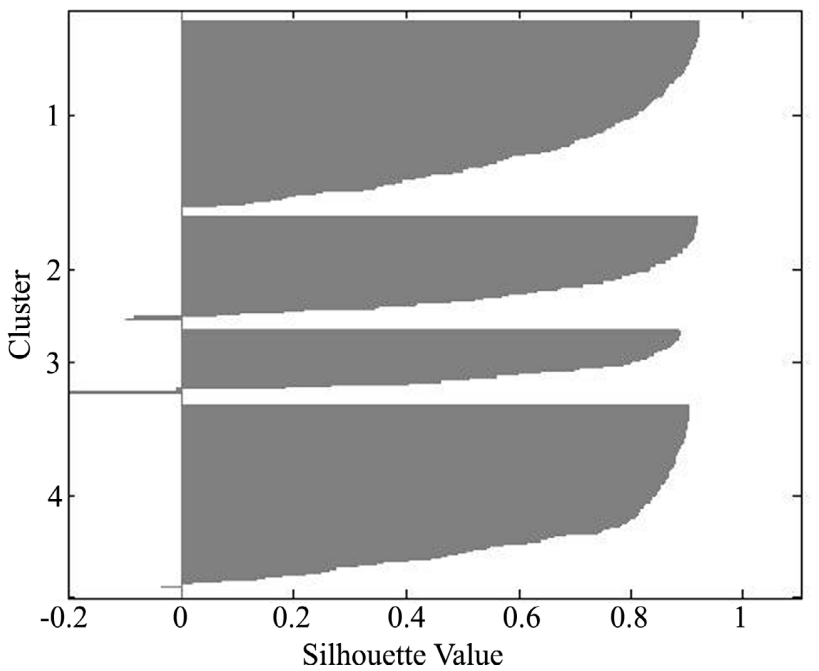

(c)

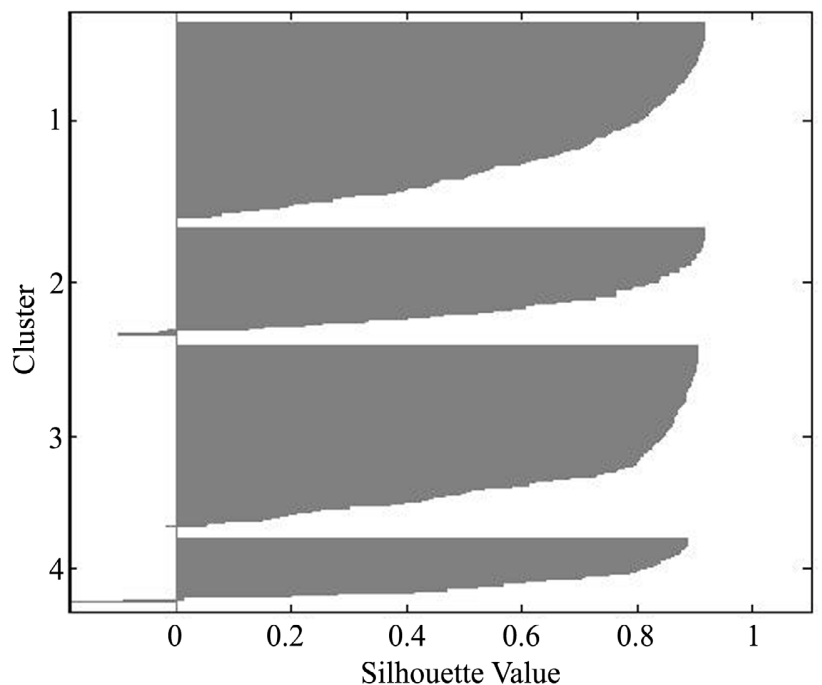

(b)

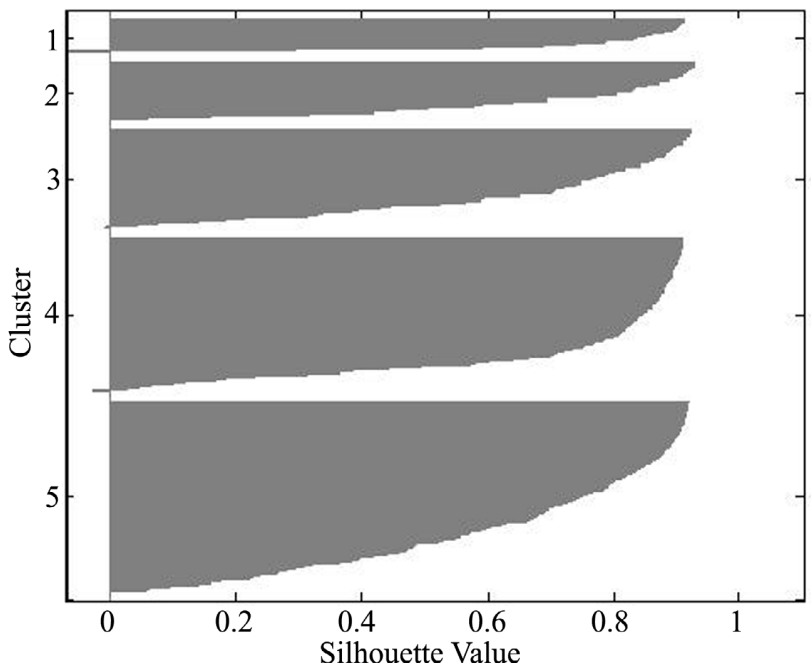

(d)

Figure 12. Cluster profiles and utility values with 3 to 6 classes related to Fe and S concentration. (a) Classification with 3 classes; (b) Classification with 4 classes with an average value of 0.883; (c) Classification with 5; (d) Classification with 6 classes. 
According to the graph of the values of the utility function related to each clustering, the three-class classification has the highest utility value among all the classifications, so in order to measure the behavior of the iron element relative to the grade sulfur element of the category centers per $K=3$ is shown diagrammatically in Figure 14.

According to the above diagram, which shows the changes in the concentration of iron versus sulfur in the Sheytoor deposit, it can be said that with increasing the concentration of iron, the concentration of sulfur decreases. The behavior of these two elements in relation to each other is nonlinear and the curve fitting on their behavior is of the quadratic equation with a correlation coefficient of $\mathrm{R}^{2}=1$. The behavioral equation of these two elements is given below (10).

$$
\mathrm{S}=-0.0002(\mathrm{Fe})^{2}+0.0084(\mathrm{Fe})+0.4086
$$

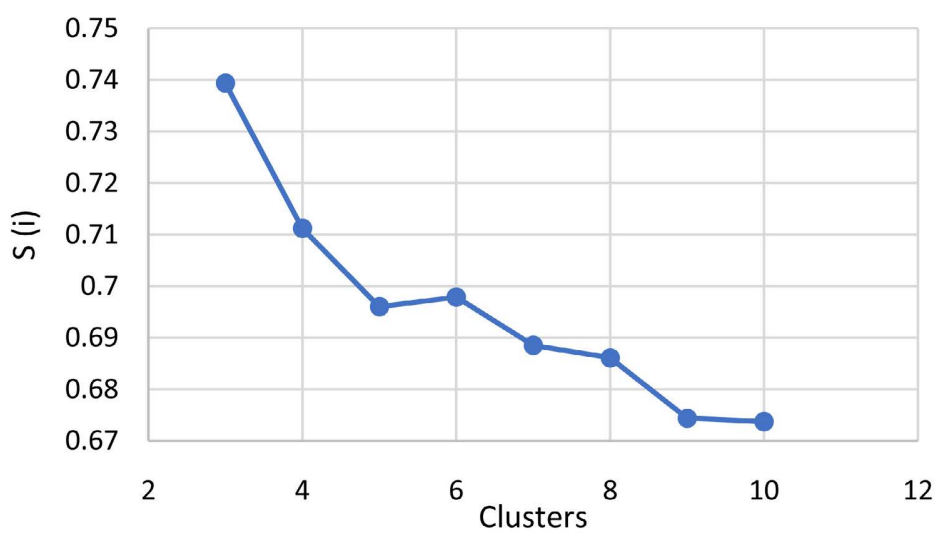

Figure 13. Graph of the average value of the utility function against the number of classes in the behavior of iron and sulfur.

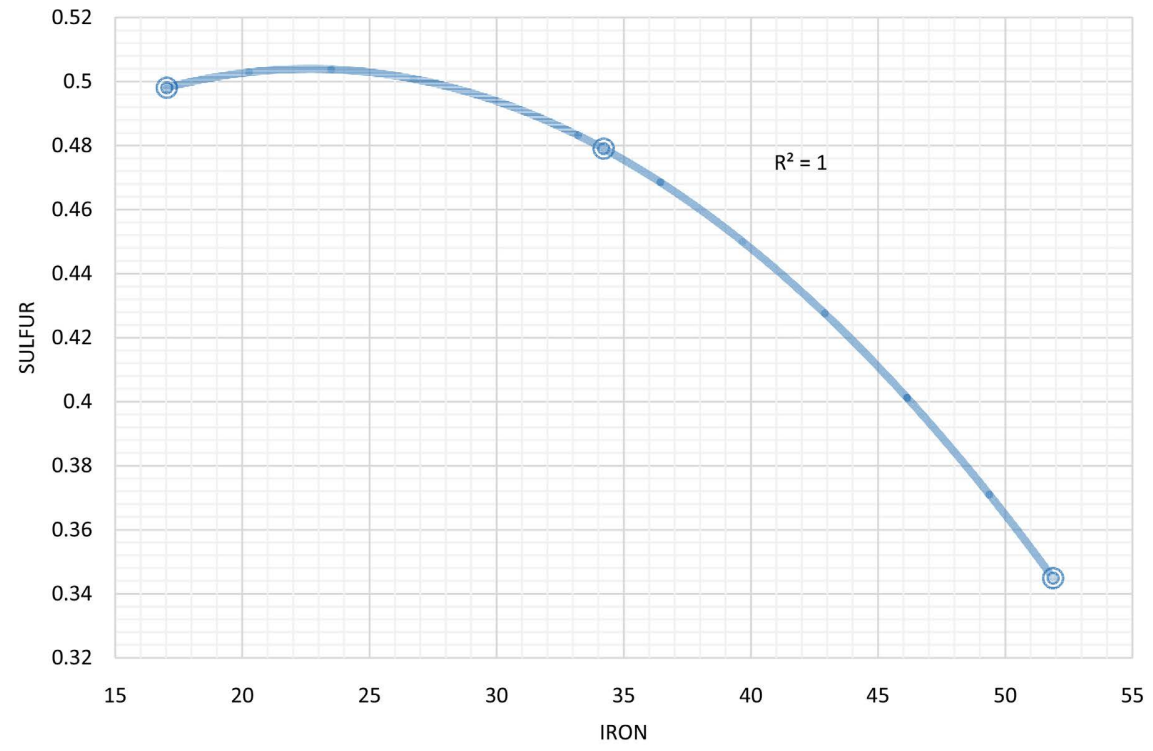

Figure 14. Concentrations of iron and sulfur in class centers for three-class clustering. 


\subsection{D Geochemical Model of $P$ and S Elements}

The three-dimensional model of mineralization and dispersion of phosphorus and sulfur elements in exploratory boreholes in order to provide a better view of mineralization in the region is given in the figure below (Figure 15).

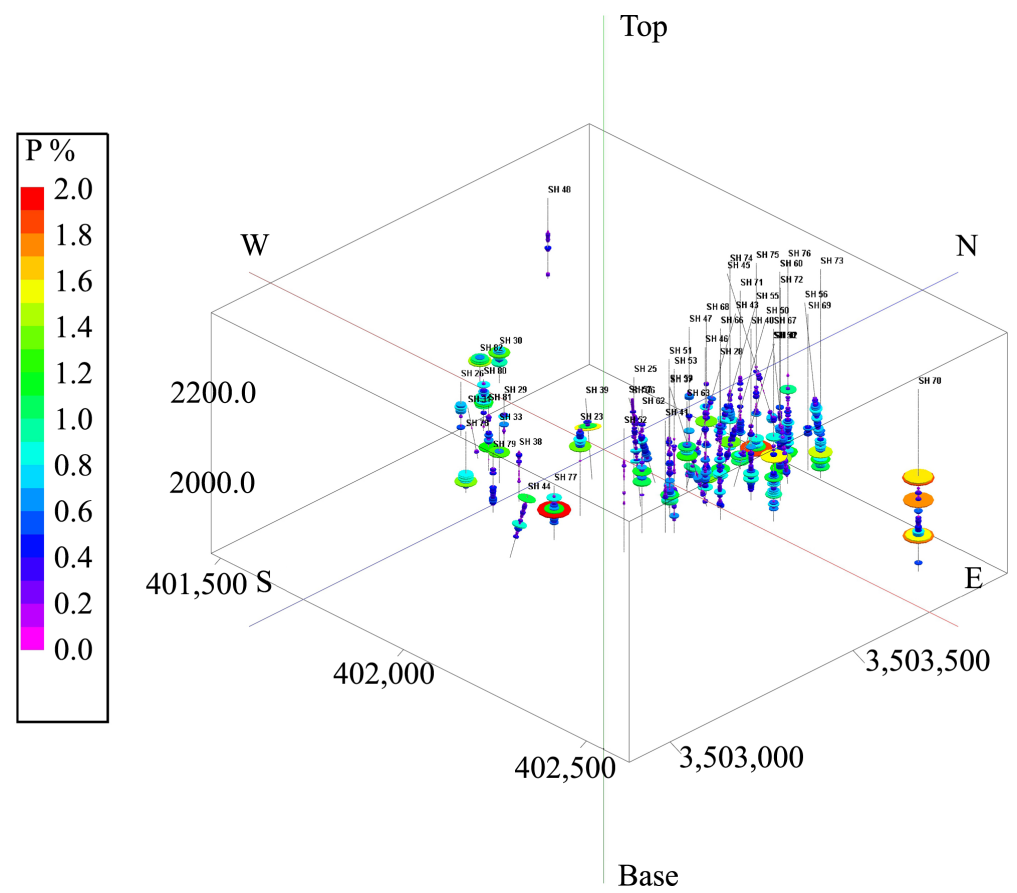

(a)

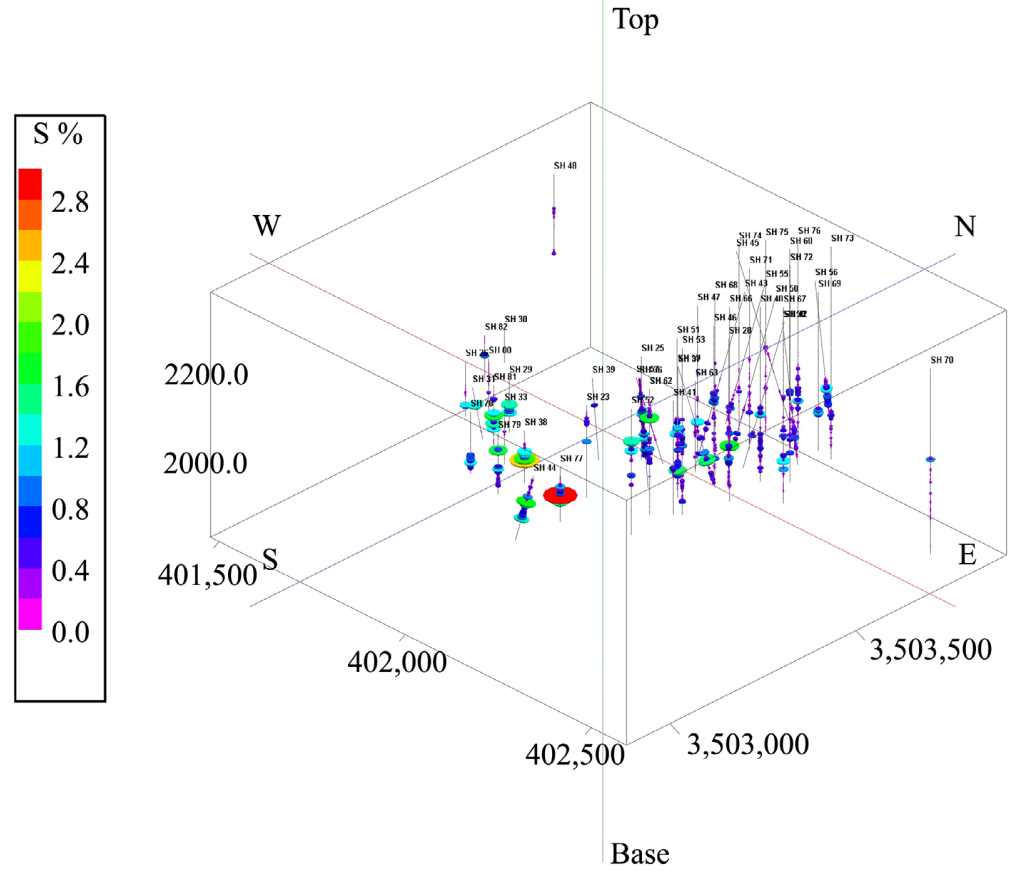

(b)

Figure 15. Dispersion of phosphorus (a) and sulfur (b) elements in exploratory boreholes drilled. 
Using the Kriging interpolation method in confined space to exploratory boreholes, the estimated titers of phosphorus and sulfur elements were calculated at points where no borehole had been drilled. The mineralization of phosphorus and sulfur elements in the area of Sheytoor deposit was modeled in three dimensions. The 3D geochemical models of $\mathrm{P}$ and $\mathrm{S}$ elements are presented in Figure 16.

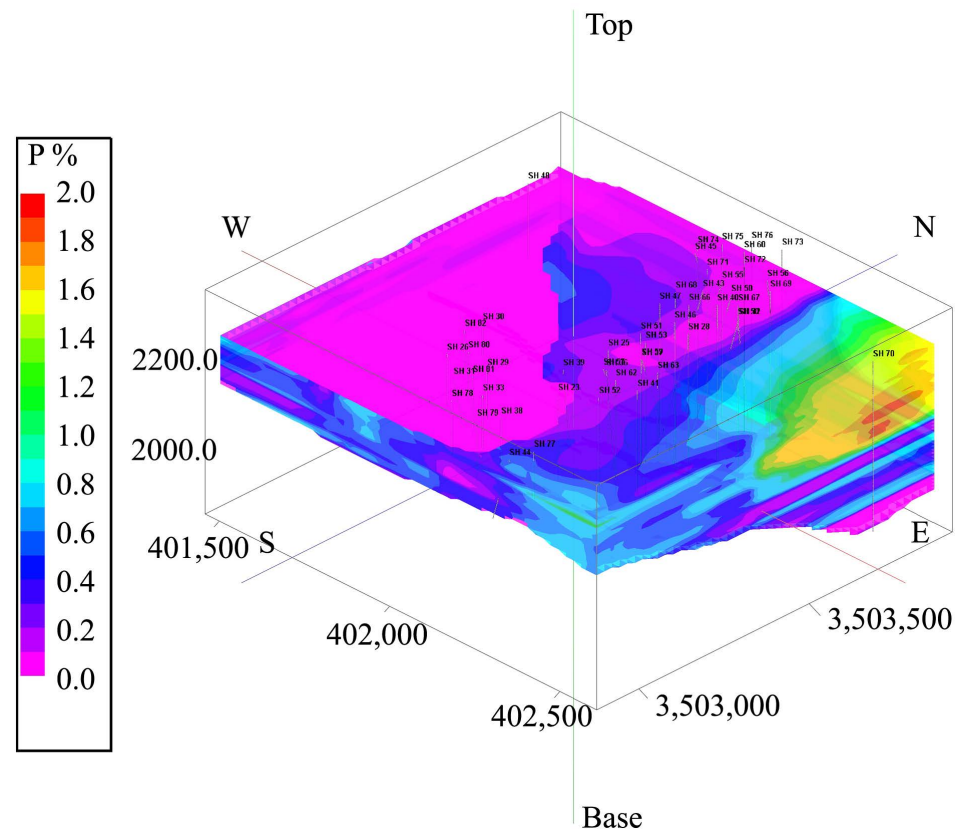

(a)

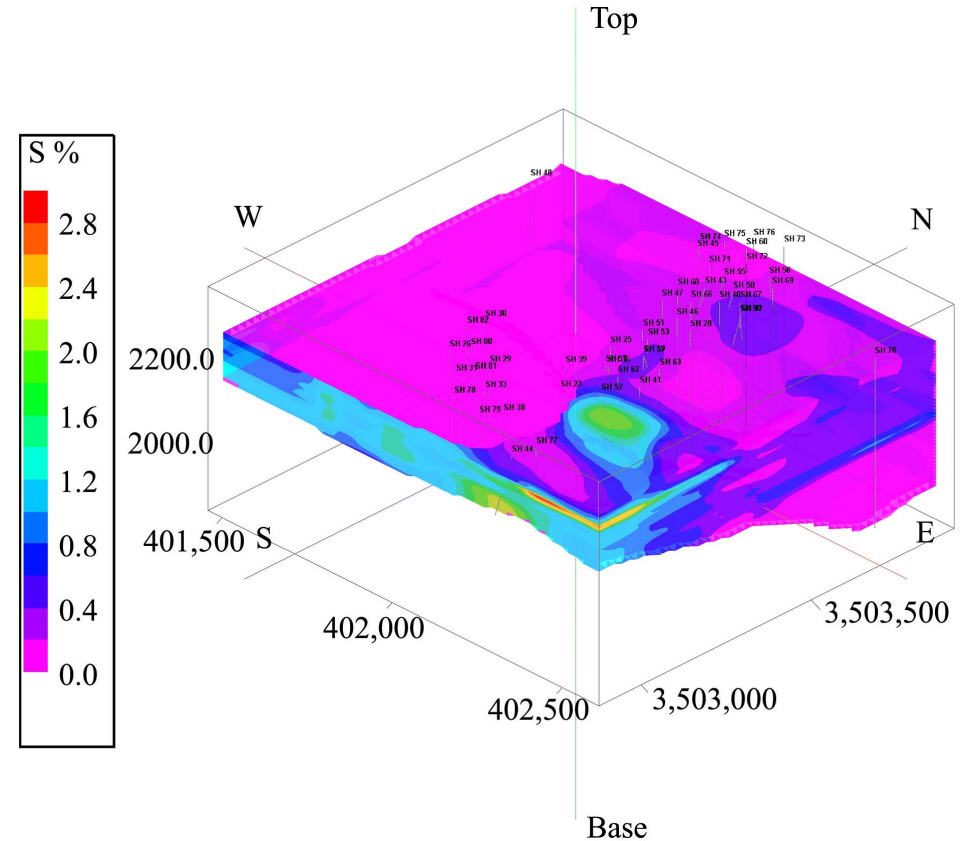

(b)

Figure 16. Estimated three-dimensional model of phosphorus element (a) and sulfur (b) mineralization-by kriging method-south-east top view. 


\subsection{Detection of $P$ and $S$ Mineralization by Concentration-Volume Fractal Method}

\subsubsection{Phosphorus Mineralization}

In order to identify the mineralized areas of phosphorus along with the mineralized areas of iron element in Sheytoor deposit, using the three-dimensional model of the dispersion of phosphorus concentration in the area obtained by kriging estimator, and by applying the concentration-volume $(\mathrm{C}-\mathrm{V})$ fractal method, fine communities were identified in the area. The threshold of background and anomaly for the element $\mathrm{P}$ were also calculated.

As shown in Figure 17, three mineralization communities have been identified for the phosphorus element. The threshold value of each of these communities is presented in Table 2.

The phosphorus mineralization enrichment community is shown in Figure 18. This $3 \mathrm{D}$ model is made taking into account the cutoff grade of $1.42 \%$.

\subsubsection{Sulfur Mineralization}

In order to match the mineralization zones of iron element with high-sulfur and low-sulfur mineralization zones, a three-dimensional model of mineralization and dispersion of sulfur element was constructed using Kriging interpolation

Table 2. Threshold grade of phosphorus mineralization communities in Kriging model.

\begin{tabular}{cc}
\hline Community & Phosphorus threshold grade \\
\hline Background & $<0.32 \%$ \\
Anomaly & $0.32 \%<<1.42 \%$ \\
Enrichment & $1.42 \%<$ \\
\hline
\end{tabular}

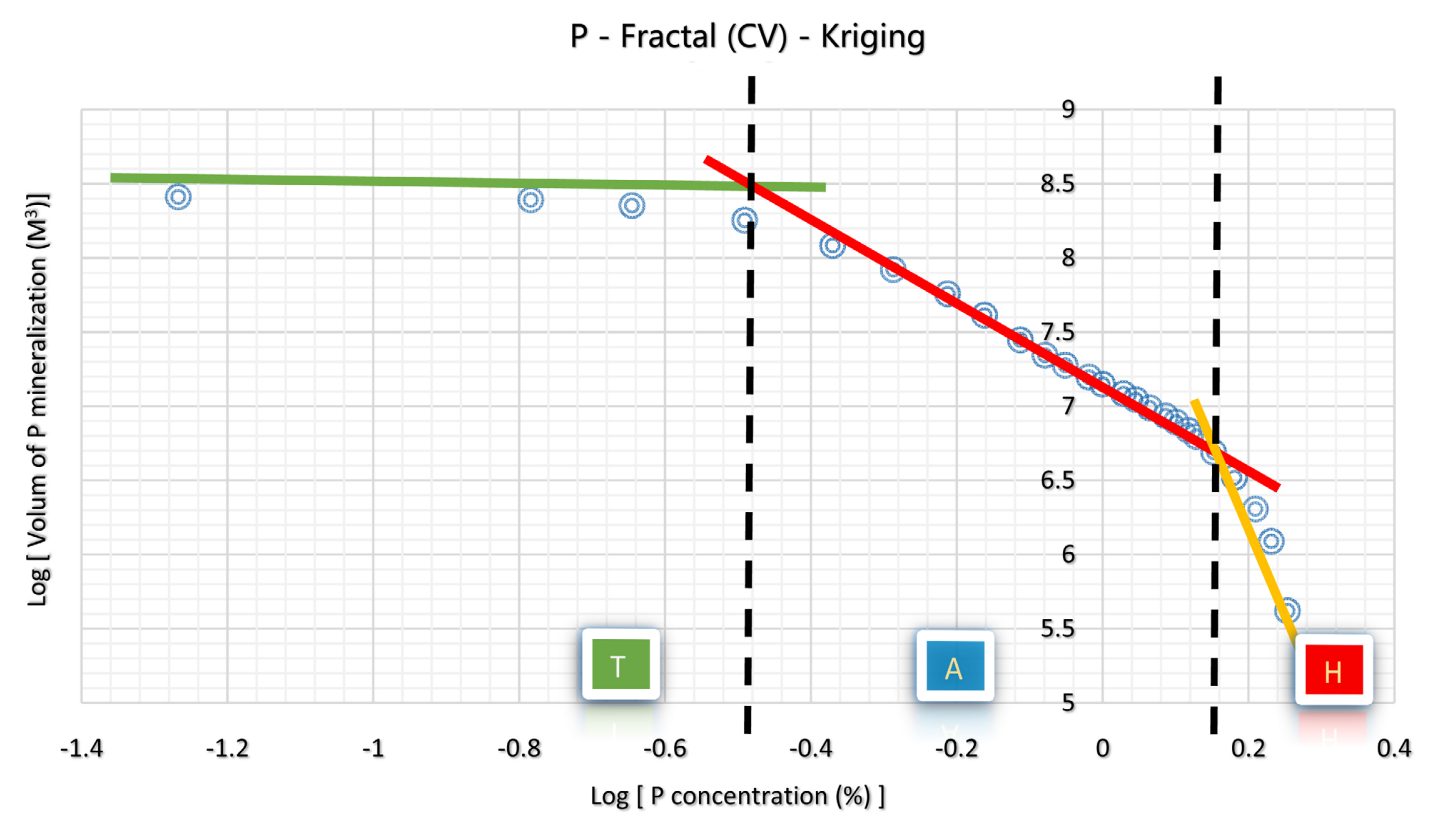

Figure 17. Separation of phosphorus mineralization grade communities using C-V fractal method. 


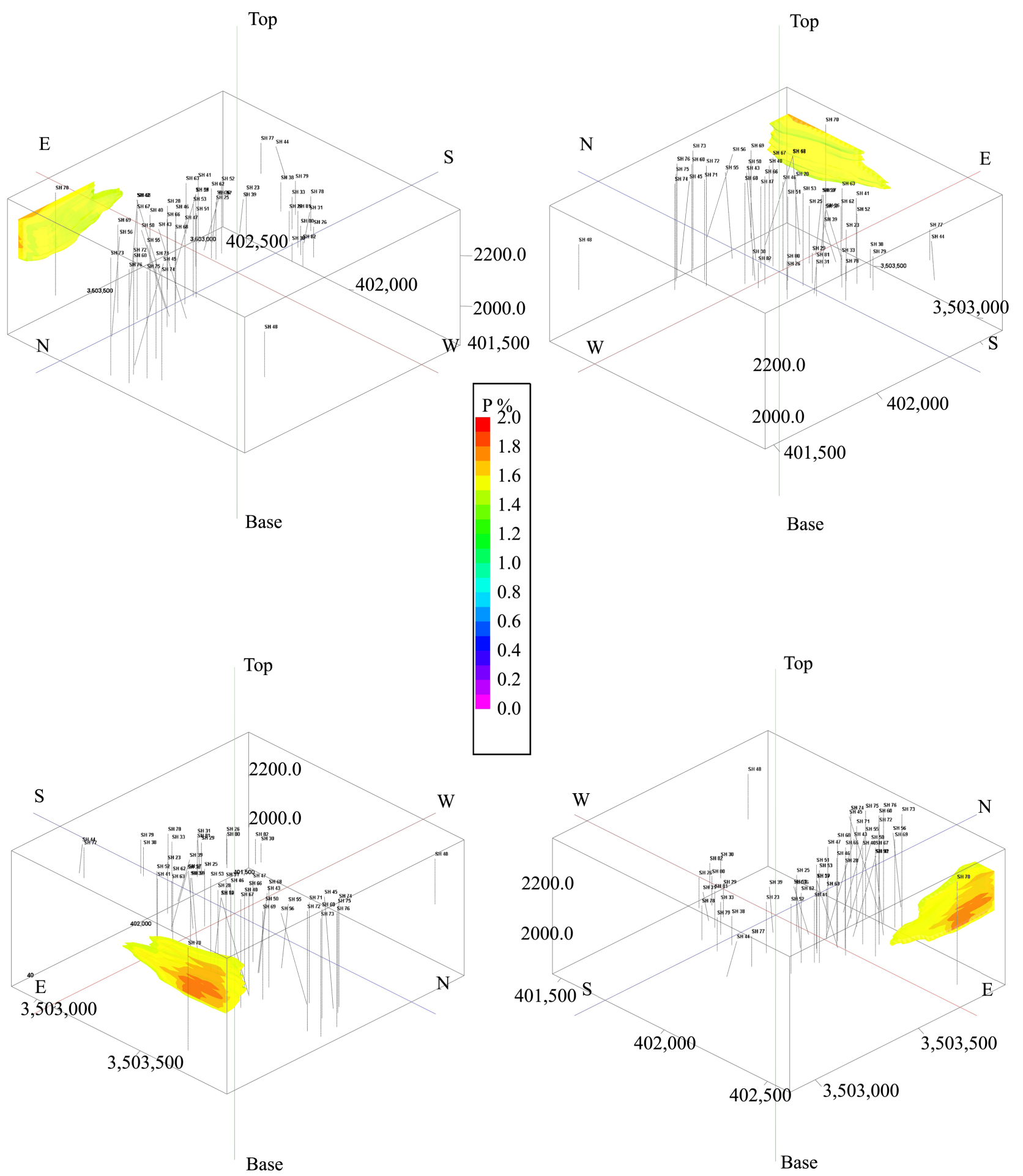

Figure 18. Three-dimensional model of mineralization of phosphorus element enrichment community-cutoff grade of $1.42 \%-$ in Kriging model.

method. Then, using the $\mathrm{C}-\mathrm{V}$ fractal method, the threshold concentration of background and anomaly were calculated. The following diagrams are related to the fractal model of volume-concentration as well as the three-dimensional model of the anomalous community. 
Based on C-V fractal diagram (shown in Figure 19), three communities of Sulfur mineralization are separated. The characteristics of these mineralization communities are presented in Table 3.

The three-dimensional model of mineralization of the anomalous sulfur mineralization community is presented in Figure 20. This model is made taking into account the cutoff grade of $1.07 \%$.

\section{Conclusions}

- The region is located in yazd province (central tectonic zone of iran). Statistical and geostatistical studies were carried out based on core data of Sheytoor iron deposit which is located near Bafgh city. The main ore deposit is as apatite-magnetite mineralization.

- In order to identify and replace the outlier data, the doerffel method was used. It was found that there is no outlier data among the geochemical data of the iron element obtained from the analysis.

- Using Kriging and Inverse Distance Weighting (IDW) interpolation methods, 3D block models were created and presented.

Table 3. Threshold grade of sulfur mineralization communities in Kriging model.

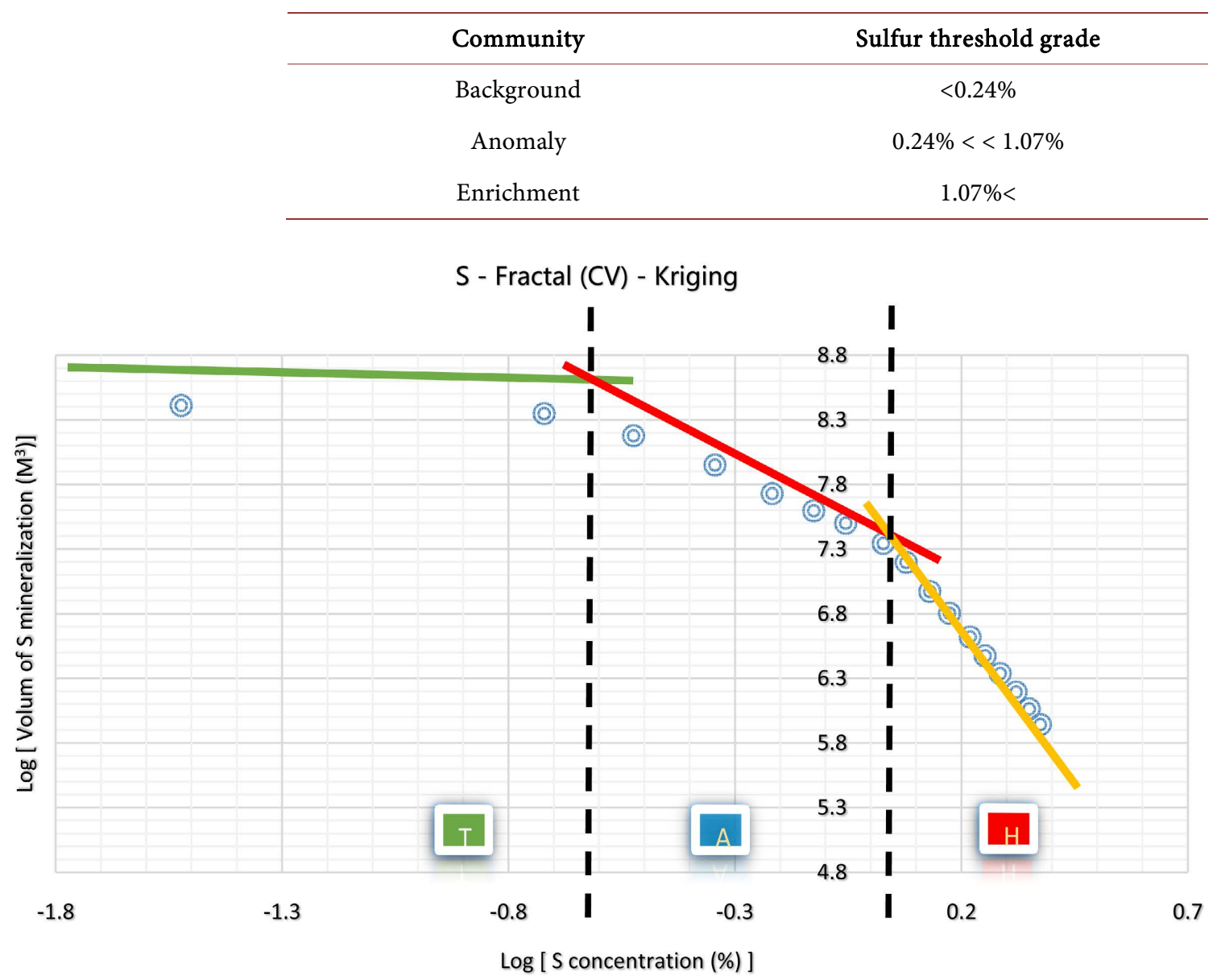

Figure 19. Separation of sulfur mineralization grade communities using C-V fractal method. 


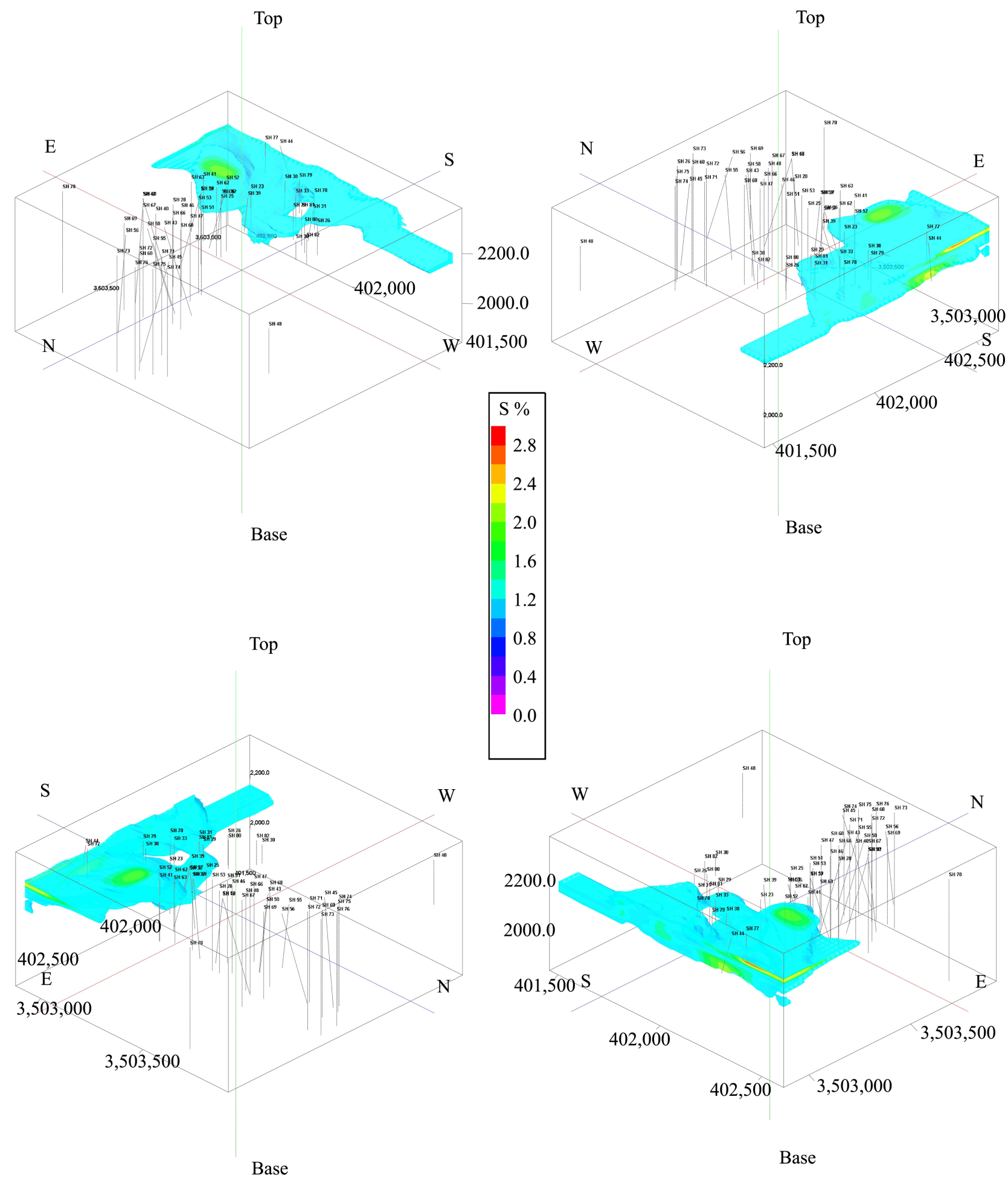

Figure 20. Three-dimensional model of mineralization of sulfur element enrichment community-cutoff grade of $1.07 \%$-in Kriging model.

- Due to the fact that phosphorus and sulfur are interfering elements in the processing and smelting of iron, so it is important to identify their geochemical behavior as well as their geochemical modeling. 
- Using the K-means clustering method, the concentration data of phosphorus and sulfur elements in relation to the element iron were classified. Then the optimal clustering was determined and based on the concentration of elements in the centers of the classes, the geochemical behavior of phosphorus and sulfur elements towards the iron element were modeled.

- After mineralization and dispersion of phosphorus and sulfur concentrations were modeled in three dimensions, mineralization communities were separated for each element using $\mathrm{C}-\mathrm{V}$ fractal method.

- The enrichment zone threshold for phosphorus and sulfur are $1.42 \%$ and $1.07 \%$, respectively. These communities were modeled three-dimensionally to adapt to iron mineralization in the Sheytoor iron ore mine.

- Mining planning can be reconsidered using three-dimensional models of mineralization of phosphorus and sulfur elements, which are considered as deleterious elements in the process of iron concentrate production and, of course, later stages such as steelmaking. It is suggested that mineral extraction specialists continue geometallurgical studies based on the information obtained from this study.

\section{Conflicts of Interest}

The authors declare no conflicts of interest regarding the publication of this paper.

\section{References}

[1] Clarke, F.W. and Washington, H.S. (1924) The Composition of the Earth's Crust, Vol. 127. US Government Printing Office, Washington DC. https://doi.org/10.3133/pp127

[2] Clarke, F.W. (1920) The Data of Geochemistry. US Government Printing Office, Washington DC.

[3] Nazerian, E., Gharebaghi, S. and Safdarian, A. (2017) Optimal Distribution Network Reconfiguration Considering Power Quality Issues. 2017 Smart Grid Conference (SGC). Tehran, 20-21 December 2017, 1-6. https://doi.org/10.1109/SGC.2017.8308877

[4] Nazerian, E. and Tahami, F. (2019) Optimum Design of Planar Transformer for LLC Resonant Converter Using Metaheuristic Method. IECON 2019-45th Annual Conference of the IEEE Industrial Electronics Society, Lisbon, 14-17 October 2019, 6621-6626. https://doi.org/10.1109/IECON.2019.8927114

[5] Veprek, S. and Veprek-Heijman, M.J. (2008) Industrial Applications of Superhard Nanocomposite Coatings. Surface and Coatings Technology, 202, 5063-5073. https://doi.org/10.1016/j.surfcoat.2008.05.038

[6] Nakamura, S. and Yamasue, E. (2010) Hybrid LCA of a Design for Disassembly Technology: Active Disassembling Fasteners of Hydrogen Storage Alloys for Home Appliances. Environmental Science \& Technology, 44, 4402-4408. https://doi.org/10.1021/es903340h

[7] Pownceby, M.I., Hapugoda, S., Manuel, J., Webster, N.A. and MacRae, C.M. (2019) Characterisation of Phosphorus and Other Impurities in Goethite-Rich Iron Ores-Possible P Incorporation Mechanisms. Minerals Engineering, 143, Article ID: 106022. https://doi.org/10.1016/j.mineng.2019.106022 
[8] Ghosh, A. and Chatterjee, A. (2008) Iron Making and Steelmaking: Theory and Practice. PHI Learning Pvt. Ltd., New Delhi.

[9] Ghorbani, M. (2013) The Economic Geology of Iran. Springer, Dordrecht. https://doi.org/10.1007/978-94-007-5625-0

[10] Shirazy, A., Ziaii, M. and Hezarkhani, A. (2020) Geochemical Behavior Investigation Based on K-Means and Artificial Neural Network Prediction for Copper, in Kivi Region, Ardabil Province, IRAN. Iranian Journal of Mining Engineering, 14, 96-112.

[11] Shirazy, A., Shirazi, A., Ferdossi, M.H. and Ziaii, M. (2019) Geochemical and Geostatistical Studies for Estimating Gold Grade in Tarq Prospect Area by K-Means Clustering Method. Open Journal of Geology, 9, 306-326.

https://doi.org/10.4236/ojg.2019.96021

[12] Shirazy, A., Shirazi, A. and Hezarkhani, A. (2018) Predicting Gold Grade in Tarq 1: 100000 Geochemical Map Using the Behavior of Gold, Arsenic and Antimony by K-Means Method. Journal of Mineral Resources Engineering, 2, 11-23.

[13] Hezarkhani, A. and Ghannadpour, S.S. (2015) Geochemical Behavior Investigation Based on K-Means Clustering: Basics, Concepts and Case Study. LAP Lambert Academic Publishing, Saarbrücken.

[14] Jain, A.K. (2010) Data Clustering: 50 Years beyond K-Means. Pattern Recognition Letters, 31, 651-666. https://doi.org/10.1016/j.patrec.2009.09.011

[15] Shirazi, A., Shirazy, A., Saki, S. and Hezarkhani, A. (2018) Introducing a Software for Innovative Neuro-Fuzzy Clustering Method Named NFCMR. Global Journal of Computer Sciences. Theory and Research, 8, 62-69. https://doi.org/10.18844/gjcs.v8i2.3264

[16] Nazerian, H., Shirazy, A., Shirazi, A. and Hezarkhani, A. (2021) Predict the Amount of $\mathrm{Cu}$ Using the Four Ca, Al, P, S Elements by Multiple Linear Regression Method. International Journal for Research in Applied Science and Engineering Technology (IJRASET), 9, 1088-1092. https://doi.org/10.22214/ijraset.2021.38121

[17] Shirazi, A., Shirazy, A., Saki, S. and Hezarkhani, A. (2018) Geostatistics Studies and Geochemical Modeling Based on Core Data, Sheytoor Iron Deposit, Iran. Journal of Geological Resource and Engineering, 6, 124-133. https://doi.org/10.17265/2328-2193/2018.03.004

[18] Alahgholi, S., Shirazy, A. and Shirazi, A. (2018) Geostatistical Studies and Anomalous Elements Detection, Bardaskan Area, Iran. Open Journal of Geology, 8, 697-710. https://doi.org/10.4236/ojg.2018.87041

[19] Shirazi, A., Hezarkhani, A., Shirazy, A. and Shahrood, I. (2018) Exploration Geochemistry Data-Application for $\mathrm{Cu}$ Anomaly Separation Based On Classical and Modern Statistical Methods in South Khorasan, Iran. International Journal of Science and Engineering Applications, 7, 39-44. https://doi.org/10.7753/IJSEA0704.1001

[20] Shirazi, A., Hezarkhani, A., Shirazy, A. and Shahrood, I. (2018) Remote Sensing Studies for Mapping of Iron Oxide Regions, South of Kerman, Iran. International Journal of Science and Engineering Applications, 7, 45-51. https://doi.org/10.7753/IJSEA0704.1002

[21] Samimi Namin, M. (2006) Report on Potential Detection and Preliminary Exploration of Iron, Gold and Copper in Sarbisheh City. Madankav Engineering Co., Tehran, $238 \mathrm{p}$.

[22] Shirazi, A., Shirazy, A. and Karami, J. (2018) Remote Sensing to Identify Copper Alterations and Promising Regions, Sarbishe, South Khorasan, Iran. International 
Journal of Geology and Earth Sciences, 4, 36-52.

[23] Shirazy, A., Ziaii, M., Hezarkhani, A. and Timkin, T. (2020) Geostatistical and Remote Sensing Studies to Identify High Metallogenic Potential Regions in the Kivi Area of Iran. Minerals, 10, Article No. 869. https://doi.org/10.3390/min10100869

[24] Shirazy, A., Shirazi, A., Heidarlaki, S. and Ziaii, M. (2018) Exploratory Remote Sensing Studies to Determine the Mineralization Zones around the Zarshuran Gold Mine. International Journal of Science and Engineering Applications, 7, 274-279. https://doi.org/10.7753/IJSEA0709.1004

[25] Shirazy, A., Shirazi, A. and Nazerian, H. (2021) Application of Remote Sensing in Earth Sciences-A Review. International Journal of Science and Engineering Applications, 10, 45-51.

[26] Yasrebi, A.B., Afzal, P., Wetherelt, A., Foster, P. and Esfahanipour, R. (2013) Correlation between Geology and Concentration-Volume Fractal Models: Significance for $\mathrm{Cu}$ and Mo Mineralized Zones Separation in the Kahang Porphyry Deposit (Central Iran). Geologica Carpathica, 64, 153-163.

[27] Shirazy, A., Shirazi, A., Nazerian, H., Khayer, K. and Hezarkhani, A. (2021) Geophysical Study: Estimation of Deposit Depth Using Gravimetric Data and Euler method (Jalalabad Iron Mine, Kerman Province of IRAN). Open Journal of Geology, 11, 340-355. https://doi.org/10.4236/ojg.2021.118018

[28] Khayer, K., Shirazy, A., Shirazi, A., Ansari, A. and Hezarkhani, A. (2020) Cementation Exponent Estimate in Carbonate Reservoirs: A New Method. Global Journal of Computer Sciences. Theory and Research, 10, 66-72.

https://doi.org/10.18844/gjcs.v10i2.5894

[29] Khayer, K., Shirazy, A., Shirazi, A., Ansari, A., Nazerian, H. and Hezarkhani, A. (2021) Determination of Archie's Tortuosity Factor from Stoneley Waves in Carbonate Reservoirs. International Journal of Science and Engineering Applications, 10, 107-110.

[30] Shirazy, A., Hezarkhani, A., Timkin, T. and Shirazi, A. (2021) Magneto-/RadioMetric Behavior in Order to Identify an Estimator Model Using K-Means Clustering and Artificial Neural Network (ANN) (Iron Ore Deposit, Yazd, IRAN). Minerals, 11 .

[31] Doodran, R.J., Khakmardan, S., Shirazi, A. and Shirazy, A. (2020) Minimalization of Ash from Iranian Gilsonite by Froth Flotation. Journal of Minerals and Materials Characterization and Engineering, 9, 1-13. https://doi.org/10.4236/jmmce.2021.91001

[32] Khakmardan, S., Doodran, R.J., Shirazy, A., Shirazi, A. and Mozaffari, E. (2020) Evaluation of Chromite Recovery from Shaking Table Tailings by Magnetic Separation Method. Open Journal of Geology, 10, 1153-1163. https://doi.org/10.4236/ojg.2020.1012055

[33] Khakmardan, S., Shirazi, A., Shirazy, A. and Hosseingholi, H. (2018) Copper Oxide Ore Leaching Ability and Cementation Behavior, Mesgaran Deposit in IRAN. Open Journal of Geology, 8, 841-858. https://doi.org/10.4236/ojg.2018.89049

[34] Shirazy, A., Shirazi, A., Nazerian, H. and Hezarkhani, A. (2021) Investigation of Geochemical Sections in Exploratory Boreholes of Mesgaran Copper Deposit in Iran. International Journal for Research in Applied Science and Engineering Technology, 9, 2364-2368. https://doi.org/10.22214/ijraset.2021.37775

[35] Yousefi, M. (2016) General and Detailed Exploration of Iron Ore Anomalies of Iran's Central Plateau, 5a Anomlay (Sheytoor-Gazestan). Madankav Engineering Co., Tehran. 
[36] Shirazi, A. and Shirazy, A. (2020) Introducing Geotourism Attractions in Toroud Village, Semnan Province, IRAN. International Journal of Science and Engineering Applications, 9, 79-86.

[37] Shirazi, A. (2018) Geochemical Investigations and Modeling on Sheytoor Iron Deposit, Bafq. Mining and Metallurgical Engineering Department, Amirkabir University of Technology, Tehran Polytechnic, Tehran.

[38] Hassanipak, A.A. and Sharafeddin, M. (2005) Exploration Data Analysis, Vol. 1. Tehran University Press, Tehran.

[39] Grubbs, F.E. (1969) Procedures for Detecting Outlying Observations in Samples. Technometrics, 11, 1-21. https://doi.org/10.1080/00401706.1969.10490657

[40] Maddala, G.S. (1992) Outliers. Introduction to Econometrics. 2nd Edition, MacMillan, New York.

[41] Kalisch, M., Michalak, M., Sikora, M., Wróbel, Ł. and Przystałka, P. (2015) Influence of Outliers Introduction on Predictive Models Quality. In: Kozielski, S., Mrozek, D., Kasprowski, P., Małysiak-Mrozek, B. and Kostrzewa, D., Eds., Beyond Databases, Architectures and Structures. Advanced Technologies for Data Mining and Knowledge Discovery. Springer, Cham, 79-93. https://doi.org/10.1007/978-3-319-34099-9_5

[42] Hassani Pak, A. (1998) Geostatistics. University of Tehran, Tehran.

[43] Cressie, N. (1990) The Origins of Kriging. Mathematical Geology, 22, 239-252. https://doi.org/10.1007/BF00889887

[44] Lu, G.Y. and Wong, D.W. (2008) An Adaptive Inverse-Distance Weighting Spatial Interpolation Technique. Computers \& Geosciences, 34, 1044-1055. https://doi.org/10.1016/j.cageo.2007.07.010

[45] Ataeipoor, M. (2006) Basics of Mineral Modeling, Vol. 1. Amirkabir University of Technology (Tehran Polytechnic) Press, Tehran.

[46] Zhou, S., Zhou, K., Wang, J., Yang, G. and Wang, S. (2018) Application of Cluster Analysis to Geochemical Compositional Data for Identifying Ore-Related Geochemical Anomalies. Frontiers of Earth Science, 12, 491-505.

https://doi.org/10.1007/s11707-017-0682-8

[47] Saha, S. and Bandyopadhyay, S. (2013) A Generalized Automatic Clustering Algorithm in a Multiobjective Framework. Applied Soft Computing, 13, 89-108. https://doi.org/10.1016/j.asoc.2012.08.005

[48] Shirazy, A., Shirazi, A. and Hezarkhani, A. (2020) Behavioral Analysis of Geochemical Elements in Mineral Exploration. LAP LAMBERT Academic Publishing, city.

[49] Afzal, P., Alghalandis, Y.F., Khakzad, A., Moarefvand, P. and Omran, N.R. (2011) Delineation of Mineralization Zones in Porphyry Cu Deposits by Fractal Concentration-Volume Modeling. Journal of Geochemical Exploration, 108, 220-232. https://doi.org/10.1016/j.gexplo.2011.03.005

[50] Afzal, P., H.D. Ahari, N.R. Omran, and Aliyari, F. (2013) Delineation of Gold Mineralized Zones Using Concentration-Volume Fractal Model in Qolqoleh Gold Deposit, NW Iran. Ore Geology Reviews, 55, 125-133.

https://doi.org/10.1016/j.oregeorev.2013.05.005

[51] Agterberg, F., Cheng, Q., Brown, A. and Good, D. (1996) Multifractal Modeling of Fractures in the Lac du Bonnet Batholith, Manitoba. Computers \& Geosciences, 22, 497-507. https://doi.org/10.1016/0098-3004(95)00117-4

[52] Spalla, M.I., Marotta, A.M. and Gosso, G. (2010) Advances in Interpretation of Geological Processes: Refinement of Multi-Scale Data and Integration in Numerical Modelling. Geological Society of London, London. 